\title{
Ocean Circulation Connecting Fram Strait to Glaciers off Northeast Greenland: Mean Flows, Topographic Rossby Waves, and Their Forcing
}

\author{
ANDREAS MÜNCHOW \\ University of Delaware, Newark, Delaware \\ JANIN SCHAFFER AND TORSTEN KANZOW \\ Alfred Wegener Institute, Bremerhaven, Germany
}

(Manuscript received 6 April 2019, in final form 30 June 2019)

\begin{abstract}
From 2014 through 2016 we instrumented the $\sim 80$-km-wide Norske Trough near $78^{\circ} \mathrm{N}$ latitude that cuts across the 250-km-wide shelf from Fram Strait to the coast. Our measurements resolve a $\sim 10-\mathrm{km}$-wide bottom-intensified jet that carries $0.27 \pm 0.06 \mathrm{~Sv}\left(1 \mathrm{~Sv} \equiv 10^{6} \mathrm{~m}^{3} \mathrm{~s}^{-1}\right)$ of warm Atlantic water from Fram Strait toward the glaciers off northeast Greenland. Mean shoreward flows along the steep canyon walls reach $0.1 \mathrm{~m} \mathrm{~s}^{-1}$ about $50 \mathrm{~m}$ above the bottom in 400-m-deep water. The same bottom-intensified vertical structure emerges as the first dominant empirical orthogonal function that explains about $70 \%-80 \%$ of the variance at individual mooring locations. We interpret the current variability as remotely forced wave motions that arrive at our sensor array with periodicities longer than 6 days. Coherent motions with a period near 20 days emerge in our array as a dispersive topographic Rossby wave that propagates its energy along the sloping canyon toward the coast with a group speed of about $63 \mathrm{~km} \mathrm{day}^{-1}$. Amplitudes of wave currents reach $0.1 \mathrm{~m} \mathrm{~s}^{-1}$ in the winter of 2015/16. The wave is likely generated by Ekman pumping over the shelfbreak where sea ice is always mobile. More than $40 \%$ of the along-slope ocean current variance near the bottom of the canyon correlates with vertical Ekman pumping velocities $180 \mathrm{~km}$ away. In contrast, the impact of local winds on the observed current fluctuations is negligible. Dynamics appear linear and Rossby wave motions merely modulate the mean flow.
\end{abstract}

\section{Introduction}

Warm Atlantic waters accelerate the melting of Greenland glaciers (Holland et al. 2008; Straneo and Heimbach 2013; Johnson et al. 2011; Mayer et al. 2018). While the details of ocean melting vary from glacier to glacier (Jackson et al. 2014; Washam et al. 2019), ocean processes contribute to retreating glaciers as heat is advected across continental shelves (Inall et al. 2014; Jackson et al. 2014). We currently do not know how the heat from the deep Atlantic Ocean crosses shallow continental shelves to reach Greenland's coastal glaciers. Presenting new observations from northeast Greenland, we show subsurface jets over sloping bottom topography that advect heat through canyons toward marine terminating glaciers in northeast Greenland such as Nioghalvfjerdsbræ

Corresponding author: Andreas Münchow, muenchow@ udel.edu
(Mayer et al. 2000; Schaffer et al. 2017, 2020) and Zachariæ Isstrøm (Mouginot et al. 2015).

Submarine canyons often enlarge across-shelf exchange of mass, buoyancy, and vorticity at both polar (Münchow and Carmack 1997) and midlatitudes (Freeland and Denman 1982). A cyclonic flow over a canyon on the shelf off Vancouver Island, Canada, for example, caused high algae blooms near the surface due to a convergence of the near-bottom frictional Ekman layer and attendant upwelling of nutrient-rich waters into the upper layer (Freeland and Denman 1982). Allen and Hickey (2010) simulated the physics of canyon upwelling while Hickey and Banas (2008) explained high productivity off the northern U.S.-Canadian west coast by interactions of the wind-driven California Current, buoyancy-driven Strait of Juan de Fuca outflow, and canyon dynamics. Coastal Greenland, too, features wind- and freshwater-driven currents (Sutherland and Pickart 2008; Münchow 2016; Håvik et al. 2017) along with prominent canyon systems (Arndt et al. 2015) that 
amplify across-shelf exchanges (Sutherland and Cenedese 2009). Off northeast Greenland such exchange moves subsurface warm offshore water toward coastal glaciers via Norske Trough (Schaffer et al. 2017), which cuts across a broad continental shelf.

Bourke et al. (1987) first described surveys of the continental shelf off northeast Greenland in 1979 and 1984 from coastal glaciers to Fram Strait near $79^{\circ} \mathrm{N}$ latitude. Belgica Bank emerged as a shallow submarine shoal between $78^{\circ}$ and $80^{\circ} \mathrm{N}$ latitude, and Norske Trough as a 400-m-deep canyon to the south and west of Belgica Bank (Fig. 1). Early investigators defined water masses, estimated geostrophic velocities (Bourke et al. 1987), and suggested northward flow along the coast (Schneider and Budéus 1995). Shelf waters near $79^{\circ} \mathrm{N}$ latitude differed from those found farther south near $77^{\circ} \mathrm{N}$ latitude, which led Budéus et al. (1997) to conclude that "there is no onedirectional throughflow of deeper waters in the trough system." More recent studies such as Richter et al. (2018) provide synoptic velocity observations that describe a largely barotropic Arctic outflow north of $79^{\circ} \mathrm{N}$, which transforms into a more baroclinic boundary current near the shelfbreak off northeast Greenland that flows south as the East Greenland Current (Håvik et al. 2017).

The first direct ocean current measurements from the shelf and canyon systems of northeast Greenland were reported by Johnson and Niebauer (1995) and Topp and Johnson (1997) during a 1992/93 experiment. Two moorings near $80^{\circ} \mathrm{N}$ (Topp and Johnson 1997) and survey data sketched out a clockwise circulation around Belgica Bank. These early measurements did not always resolve the internal Rossby radius $R_{i} \sim 10 \mathrm{~km}$ that scales stratified flows on a rotating earth (Gill 1982). This scale is similar to the width of sloping topography, which is small relative to the 80-km-wide canyon. Our 2014-16 mooring and survey data resolve ocean currents at this scale across both slopes of the wide canyon.

Sea ice always covers the ocean off northeast Greenland (Reeh et al. 2001). During the twentieth century the continental shelf featured large areas of fastice throughout the year (Hughes et al. 2011). The general clockwise circulation around Belgica Bank (Budéus and Schneider 1995) under the fast-ice then created a polynya to the north of the fast-ice whose biological productivity functioned as a carbon sink (Yager et al. 1995). More recently, satellite imagery shows that this landfast ice breaks up for about two months in summer of the twenty-first century (Sneed and Hamilton 2016). Our observations from 2014 through 2016 thus describe ocean currents during both summer and winter

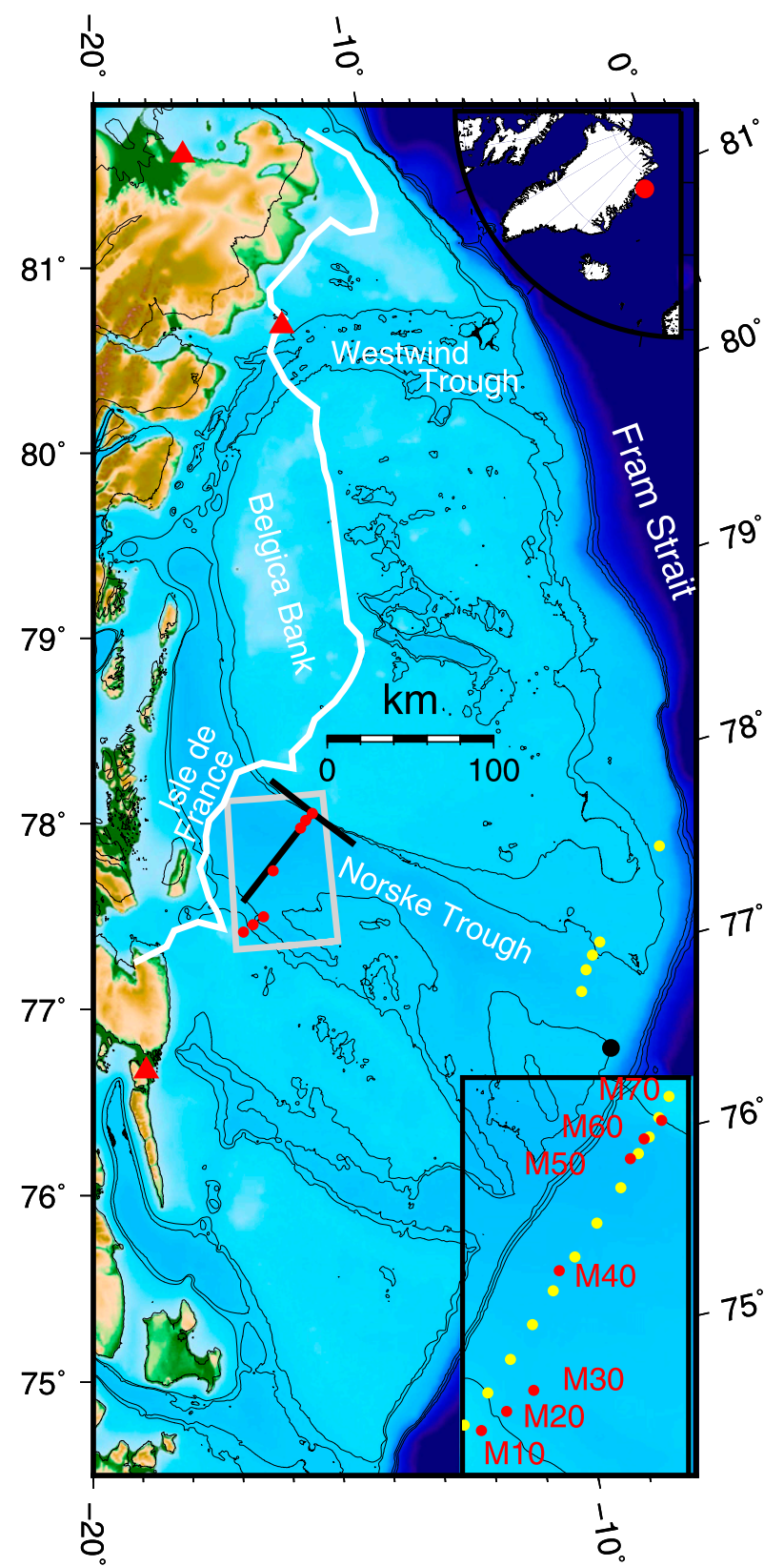

FIG. 1. Map of Northeast Greenland with 2014-16 mooring array near Île-de-France across Norske Trough. Red triangles place weather data from Station Nord $\left(81.2^{\circ} \mathrm{N}\right)$, Henrik Krøyer Holme $\left(80.5^{\circ} \mathrm{N}\right)$, and Denmark Havn $\left(76.9^{\circ} \mathrm{N}\right)$. The gray box indicates the area of mooring locations (red symbols) with local along-slope $\left(308^{\circ} \mathrm{T}\right)$ and across-slope $\left(218^{\circ} \mathrm{T}\right)$ orientation indicated by black axes. Black contours indicate 250- and 300-m depth on the continental shelf (light blue) and 1000-, 1100-, and 1200-m water depths at the shelf break of Fram Strait (dark blue). The white contour indicates maximal offshore extent of landfast sea ice in 2014. Yellow symbols are CTD station locations. The inset at the top right shows our study area off Greenland as a red dot while the inset at the bottom right details locations of seven moorings in red and 12 CTD casts from 2016 in yellow. 
TABLE 1. Mooring locations and records. Design B moorings average 120 pings per ensemble every 30 min while design A moorings average 40 pings every $2 \mathrm{~h}$. Both mooring designs have $8-\mathrm{m}$ vertical bin sizes. Heading is the magnetic compass correction from a complex (vector) correlation of tidal currents against model predictions at depth $H_{\text {model }}$ with $r^{2}$ the fraction of the correlated variance. Mooring M70 was deployed 2014-15 as M71, to be redeployed 2015-16 as M72 with a 30-h gap on 29-30 Aug 2015 between the two records.

\begin{tabular}{|c|c|c|c|c|c|c|c|c|}
\hline Name & Longitude $\left({ }^{\circ} \mathrm{W}\right)$ & Latitude $\left({ }^{\circ} \mathrm{N}\right)$ & Depth (m) & $H_{\text {model }}(\mathrm{m})$ & Bins & Design & Heading & $r^{2}$ \\
\hline M10 & 16.2972 & 77.3898 & 173 & 161 & 17 & B & -18.6 & 0.753 \\
\hline M20 & 16.0458 & 77.4257 & 272 & 268 & 30 & $\mathrm{~B}$ & 12.1 & 0.848 \\
\hline M30 & 15.7753 & 77.4653 & 303 & 305 & 32 & B & 33.4 & 0.880 \\
\hline M40 & 15.4420 & 77.7092 & 369 & 374 & 41 & $\mathrm{~B}$ & -48.0 & 0.890 \\
\hline M50 & 14.6478 & 77.9252 & 456 & 453 & 49 & A & -0.6 & 0.751 \\
\hline M60 & 14.5020 & 77.9632 & 402 & 409 & 45 & B & 45.6 & 0.668 \\
\hline M71 & 14.3102 & 77.9975 & 250 & 347 & 24 & A & 0.0 & 0.772 \\
\hline M72 & 14.3102 & 77.9975 & 250 & 347 & 24 & A & -11.8 & 0.779 \\
\hline
\end{tabular}

seasons when the coastal sea ice is mobile and landfast, respectively.

We use a diverse set of data to describe how ocean currents, temperature, sea ice, and winds are distributed in time and space on the vast continental shelf off northeast Greenland. Ocean current moorings across Norske Trough form the focus of our study that was designed to quantify dominant vertical and horizontal scales. These scales relate to dynamics that must be resolved to adequately describe across-shelf exchange of heat and buoyancy. We quantify the hypothesis that topographic Rossby waves contribute to the temporal variability of bottom-intensified currents (Rhines 1970; Pickart and Watts 1990) and that a spatially variable wind field over the slope of Fram Strait generates such waves with 20 -day periods. Alternative generation mechanisms exist and we speculate about spatially coherent oscillations with periods of 6 and 11 days.

\section{Study area, data, and methods}

Norske Trough connects deep Fram Strait in the east to coastal glaciers in the west. The trough starts as broad topographic depression near longitude $10^{\circ} \mathrm{W}$, narrows to $80 \mathrm{~km}$ near Île-de-France at latitude $77^{\circ} \mathrm{N}$, and narrows farther to $30 \mathrm{~km}$ adjacent to a chain of islands (Fig. 1). The canyon cuts across the $300-\mathrm{km}$-wide continental shelf (Arndt et al. 2015).

In June 2014 we deployed seven moorings to measure ocean currents and water properties in Norske Trough, which serves as a potential pathway from the deep ocean to coastal glaciers off northeast Greenland such as Nioghalvfjerdsbræ and Zachariæ Isstrøm (Fig. 1). We recovered all instruments more than 2 years later in August 2016 (Table 1). Each mooring included 75-kHz acoustic Doppler current profilers (ADCPs) of Teledyne RD Instruments.

We employed two distinct mooring designs (Table 1): two ADCPs contain batteries inside the pressure housing that also contains electronics and transducer assemblies (design A). The two ADCPs were mounted inside a cage shackled to a standard mooring line containing additional instruments. The ADCP can pitch, roll, and swivel on the mooring line. Tilt sensors measure these mooring motions. In contrast, five ADCPs have their transducers placed $3 \mathrm{~m}$ above the bottom atop a flat steel buoy (design B). External battery cases, acoustic releases, SeaBird SBE37sm Microcats, and additional steel buoys are all mounted within a single stiff frame that can pitch and roll, but not swivel (Münchow and Melling 2008). No additional mooring lines or sensors are above the ADCP transducer heads. The torsionally rigid design minimizes compass errors, if one knows the fixed orientation of the instrument on the sea floor. Appendix A describes data processing details to transform data into a common Earth-referenced coordinate system.

Bottom-mounted ADCPs depend on scatterers in the water column to reflect sound back to the transducers to estimate the Doppler shift in the transmit frequency $F_{0}=75 \mathrm{kHz}$ in vertical bins $D=8 \mathrm{~m}$. Our broadband ADCPs use two encoded pulses with an ambiguity velocity $V_{a}=1.75 \mathrm{~m} \mathrm{~s}^{-1}$ and beam angle $\theta=30^{\circ}$. Random single-ping velocity errors thus are (RD Instruments 1996)

$$
\sigma=\frac{150 V_{a}}{\pi}\left[\frac{\left(1 / R^{2}-1\right) 2 C \cos (\theta)}{F_{0} D}\right] .
$$

For our two-pulse system the ideal correlation $R$ is 0.5 , speed of sound $C$ is $1440 \mathrm{~m} \mathrm{~s}^{-1}$, and the standard deviation $\sigma$ becomes $0.096 \mathrm{~m} \mathrm{~s}^{-1}$. This uncertainty is reduced as $M^{-1 / 2}$ for $M$ independent pings. The ADCPs of design A sampled $M=40$ acoustic pings every two hours while the ADCPs of design B sampled 120 velocity pings every half hour. We thus estimate measurement uncertainties of 0.015 and $0.009 \mathrm{~m} \mathrm{~s}^{-1}$ for designs $\mathrm{A}$ and $\mathrm{B}$, respectively. 
TABLE 2. Basic statistics of depth-averaged currents. Mean directions and ellipse orientations are in degrees positive counterclockwise from true east. The degrees of freedom (dof) are determined as the ratio of the record length $T=792$ days and the integral decorrelation time scale $T_{d}$. Mean flows are not significantly different from zero at $95 \%$ confidence at M10 and M20 for speed. Uncertainties in directions are $95 \%$ confidence limits from directional statistics that use dof and a mean resultant length $R$ of current vectors on a unit circle (Mardia 1972).

\begin{tabular}{|c|c|c|c|c|c|c|c|}
\hline Name & Distance $(\mathrm{km})$ & Mean speed $\left(\mathrm{cm} \mathrm{s}^{-1}\right)$ & Direction $\left(^{\circ}\right)$ & $R$ & Major/minor axis $\left(\mathrm{cm} \mathrm{s}^{-1}\right)$ & Orientation $\left(^{\circ}\right)$ & dof \\
\hline M10 & 7 & $0.8 \pm 0.9$ & $180 \pm 180$ & 0.11 & $8.4 / 4.2$ & 64 & 140 \\
\hline M20 & 14 & $1.4 \pm 1.5$ & $-106 \pm 70$ & 0.15 & $7.1 / 4.3$ & 78 & 90 \\
\hline M30 & 22 & $1.8 \pm 1.5$ & $-68 \pm 40$ & 0.25 & $7.0 / 4.5$ & 81 & 73 \\
\hline M40 & 46 & $0.7 \pm 0.7$ & $-158 \pm 50$ & 0.14 & $4.9 / 4.1$ & 71 & 143 \\
\hline M50 & 76 & $2.4 \pm 1.1$ & $137 \pm 20$ & 0.35 & $6.9 / 4.1$ & 137 & 157 \\
\hline M60 & 82 & $6.7 \pm 1.2$ & $142 \pm 7$ & 0.69 & $9.2 / 3.8$ & 138 & 209 \\
\hline M70 & 87 & $4.1 \pm 1.3$ & $156 \pm 17$ & 0.41 & $9.2 / 4.9$ & 131 & 167 \\
\hline
\end{tabular}

Scatterers appear intermittently during the winter below the sea ice causing gaps in the data. We fill gaps shorter than a day by interpolating velocities in time for each vertical bin. First, we replace all "bad" velocity values with tidal predictions that we determine from the "good" values. The tidal fit includes four semidiurnal $\left(\mathrm{M}_{2}, \mathrm{~S}_{2}, \mathrm{~N}_{2}, \mathrm{~K}_{2}\right)$ and three diurnal $\left(\mathrm{K}_{1}\right.$, $\mathrm{O}_{1}, \mathrm{P}_{1}$ ) components. Second, for every daily interval with more than eight hourly values, we interpolate missing values for each 24-h segment after the tidal predictions are removed. The first step fills all gaps with a small albeit deterministic current oscillation. The second step fills gaps shorter than $16 \mathrm{~h}$ with a biharmonic spline using only detided "good" velocity estimates. The tides are added back after the spline interpolation. This procedure removes all data gaps. In a final step, the time series are filtered with a Lanczos raised cosine filter with a half-power point near $34 \mathrm{~h}$ and a window width of $75 \mathrm{~h}$ to remove tidal and inertial oscillations (Walters and Heston 1982). These filtered values are then subsampled into daily values that represent subtidal ocean current variability.

Estimating uncertainty for speed and direction of ocean currents, we use $95 \%$ confidence levels (Table 2). Speed estimates are assumed to originate from a Gaussian distribution where velocity vectors have a decorrelation time scale $T_{d}$ that varies between 4 and 12 days depending on location. We determine $T_{d}$ from a lagged autocovariance function that we integrate to its first zero crossing (Kundu and Allen 1976). Uncertainties in directions are $95 \%$ confidence limits from directional statistics that use the von Mieses' probability distribution on a unit circle from which a mean resultant length $R$ of current vectors on a unit circle (Mardia 1972) are used.

During mooring deployment in June 2014 and recovery in August 2016 we measured ocean water properties with a SeaBird 911+ conductivity-temperature-depth
(CTD) sensor package that was calibrated at the factory a few month prior and after each expedition (Schaffer et al. 2017). Salinity estimates were compared at sea against measured salinities from discrete water samples via salinometer.

Atmospheric observations are available from the Danish Meteorological Institute at Station Nord $\left(81.6^{\circ} \mathrm{N}\right.$, $\left.16.7^{\circ} \mathrm{W}\right)$, Hendrik Krøyer Holme Island $\left(80.7^{\circ} \mathrm{N}, 13.7^{\circ} \mathrm{W}\right)$, and Danmark Havn (Fig. 1). Both Station Nord and Danmark Havn are located near mountainous terrain and wind vectors from these stations do not necessarily represent conditions on the continental shelf as do data from an automated weather station on uninhabited Hendrik Krøyer Holme Island. For the 822 days of our study period from 1 June 2014 through 31 August 2016 we have 695 daily wind observations at Hendrik Krøyer Holme Island. These wind and air temperature data are accessed from NOAA's National Centers for Environmental Information as hourly values (https://www.ncei.noaa.gov/data/) that we bin into daily averages. The observations compare favorably to estimates from the European Center for Medium-Range Weather Forecasting ERA-Interim reanalysis products (Dee et al. 2011) of 10-m wind vectors and 2-m air temperatures (not shown).

Remotely sensed surface conditions originate from daily observations of microwave SSM/I and optical MODIS satellites, respectively. We use SSM/I sea ice concentrations data from NSIDC archives at $25-\mathrm{km}$ resolution (Steffen and Schweiger 1991) while MODIS data are surface reflectance at $865 \mathrm{~nm}$ obtained from NASA's Goddard Space Flight Center at 250-m resolution.

\section{Sea ice and atmospheric conditions}

In polar regions the distribution of sea ice in time and space determines how the atmosphere forces the ocean in at least two ways. Mobile sea ice can enhance the 

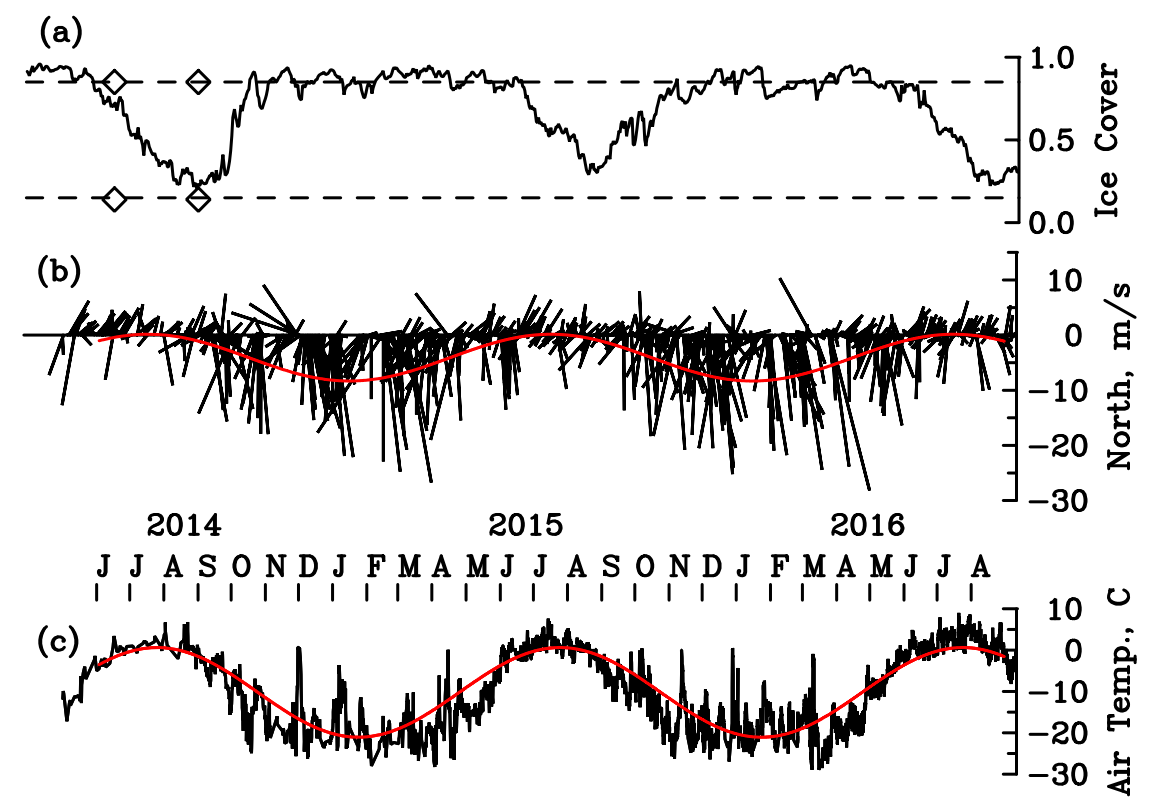

FIG. 2. (a) Sea ice cover, (b) wind vectors, and (c) air temperatures from an automated weather station at Henrik Krøyer Holme from 1 Jun 2014 through 31 Aug 2016. The fractional sea ice cover in (a) is from daily SSM/I imagery estimated for the small boxed area shown in Fig. 1. Red lines in (b) and (c) indicate variations due to a mean and annual signal fitted to the data. Dashed lines in (a) indicate $15 \%$ and $85 \%$ ice cover and symbols indicate time of satellite imagery of ice cover that we show in Fig. 3.

frictional coupling and thus momentum flux between atmosphere and the ocean, because the roughness elements of ridged sea ice are larger than that of an ice free sea surface (Lüpkes and Birnbaum 2005; Martin et al. 2014). In contrast when densely packed sea ice becomes less mobile, then it can shut down local wind forcing as it does in winter over coastal areas of the northeast Greenland continental shelf (Hughes et al. 2011). Hence, we next provide a description of sea ice and winds to reveal the seasonality that impacts our ocean current observations.

Sea ice covers most of the northeast Greenland shelf for most the year. Figure 2a shows a time series of daily sea ice concentrations. We quantify the sea ice cover by averaging daily SSM/I passive microwave data over an area that includes our mooring locations (Fig. 1). From October through June in 2015 and 2016 we find that about $85 \%$ of our study area is covered by sea ice (Fig. 2a). The sea ice minimum occurs the last two weeks in August when only about $20 \%$ of our area is covered by mobile sea ice (Fig. 3). Ice cover diminishes slowly for 2 months in June and July as a result of sea ice melting and dispersal, but it reforms rapidly within 2 weeks in October of 2014 and within 4 weeks in September and October of 2015.

Visualizing the spatial sea ice distribution, we show in Fig. 3 two MODIS Terra images. The first image on 15 June 2014 coincides with the mooring deployment in partially open water with many large and mobile floes. About $80 \mathrm{~km}$ to the north and west, however, the ice cover is $100 \%$ and immobile, that is, landfast sea ice covers a coastal area about $100 \mathrm{~km}$ wide and $250 \mathrm{~km}$ long between $78^{\circ}$ and $80^{\circ} \mathrm{N}$ latitude. We indicate this area by the yellow contour in Fig. 3 that we also use as an estimate of maximal extent of the landfast sea ice. In years past, this landfast ice survived the entire summer but this is no longer the case (Hughes et al. 2011; Sneed and Hamilton 2016). The image of 30 August 2014 depicts a small remnant of this landfast sea ice in the form of a roughly $80-\mathrm{km}$ long and $30-\mathrm{km}$-wide segment near $79^{\circ} \mathrm{N}$ and $14^{\circ} \mathrm{W}$ (Fig. 3). Most of the shelf area in August, however, is covered by mobile sea ice that is advected and dispersed by winds and ocean currents while it melts in response to solar heating.

Air temperatures over the ocean range from $-30^{\circ} \mathrm{C}$ in October-May to $+10^{\circ} \mathrm{C}$ in July-August (Fig. 2c). We estimate seasonal air temperatures by fitting observations against $T_{\text {air }}(t)=T_{0}+T_{1} \times \cos (\omega t-\phi)$, where $\omega$ represents the known annual frequency and $T_{1}$ and $\phi$ the amplitude and phase of the annual cycle. Minimizing the least squares between data and fit, we find that the mean temperature is $T_{0}=-10.2^{\circ} \pm 0.6^{\circ} \mathrm{C}$ that varies seasonally by $T_{1}=10.8^{\circ} \pm 1.2^{\circ} \mathrm{C}$. The phase indicates temperature maxima on about $25 \mathrm{July}$. Uncertainties are 

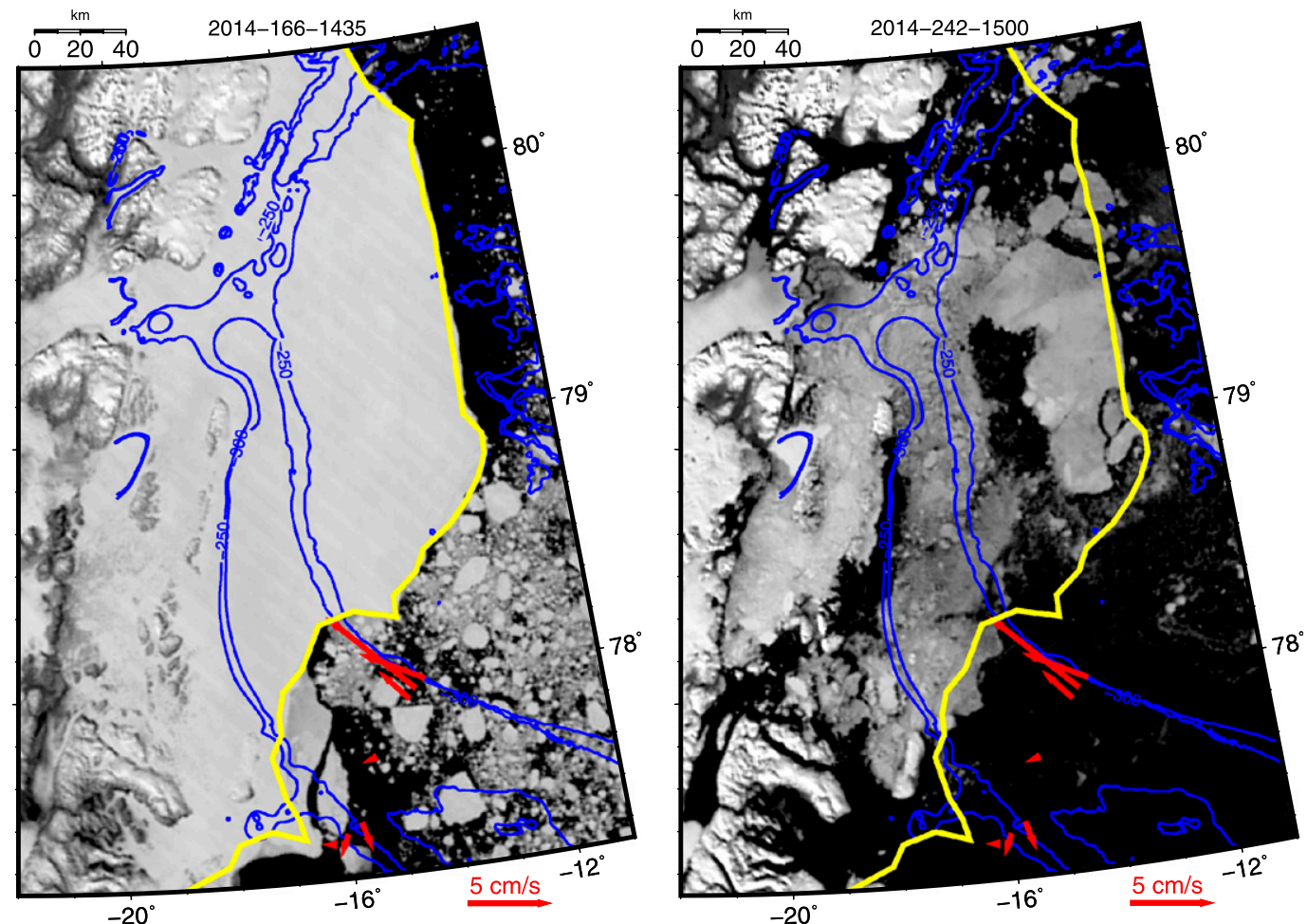

FIG. 3. Visible image of study area on (left) 15 Jun 2014 and (right) 30 Aug 2014 from MODIS Terra. Red vectors represent the depth-averaged, time-mean currents at seven mooring locations (Table 2). Bottom contours (blue) and 2014 extent of landfast sea ice (yellow) are the same as in Fig. 1. Note the landfast ice in June to the north of our mooring locations that became mobile ice in August.

95\% confidence limits assuming Gaussian noise and a decorrelation time scale of 4 days.

Observed wind vectors on Hendrik Krøyer Holme Island appear largely in phase with air temperatures. Largest winds to the south coincide with minimal air temperatures on about 25 of January. Seasonal wind variations have an amplitude of $4.2 \pm 1.8 \mathrm{~m} \mathrm{~s}^{-1}$ about the mean of $3.5 \pm 0.9 \mathrm{~m} \mathrm{~s}^{-1}$ along the north-south principal axis of variation (Fig. 2b). Observed winds during the cold season frequently exceed $20 \mathrm{~m} \mathrm{~s}^{-1}$ over the generally landfast sea ice on the continental shelf. Strong but short-lived warming events occur in winter such as in November 2014, April 2015, and February 2016 when winds from the north reverse and bring warm air from open Fram Strait waters in the southeast.

\section{Hydrography}

Schaffer et al. (2017) reviews all available hydrography for the entire shelf area to note subsurface temperature maxima in the 800-km-long trough system between $76^{\circ}$ and $80^{\circ} \mathrm{N}$ latitude. Averaging data into $100-\mathrm{km}$ bins along the trough system below 200-m depth, they find waters during the $2000-16$ period to be about $0.5^{\circ} \mathrm{C}$ warmer than those observed during the 1979-99 period. In contrast, we here focus on the vertical and acrossslope structure of the temperature and salinity fields. Figure 4 shows 2014 and 2016 summer snapshots of the local hydrography along with measurement locations of both CTD survey and ADCP mooring data labeled M10 through M70 (Table 1).

In both 2014 and 2016 we find the warmest waters below 250-m depth adjacent to the northeastern rim of the trough system. In June of 2014 (Fig. 4, left) potential temperatures reach values above $+1.5^{\circ} \mathrm{C}$ almost across the entire section at depths below $300 \mathrm{~m}$, but temperatures reach $+1.7^{\circ} \mathrm{C}$ for a CTD cast at $75 \mathrm{~km}$. The salinity distributions are almost level across the section except for a $5-\mathrm{km}$-wide area over the northeastern slope at $85 \mathrm{~km}$ where we will find the core of the subsurface jet. Maximal ocean temperatures in August of 2016 are $+1.8^{\circ} \mathrm{C}$ near $300-\mathrm{m}$ depth (Fig. 4 , right). The subsurface temperature maximum appears as a $15-\mathrm{km}$-wide and 50-m-thick intrusion that is attached to the northeastern rim of the canyon. Furthermore, we find upward sloping salinity contours near $80 \mathrm{~km}$ within which the local temperature maximum is embedded. Dynamically this is consistent with a northward geostrophic flow below 150-m 

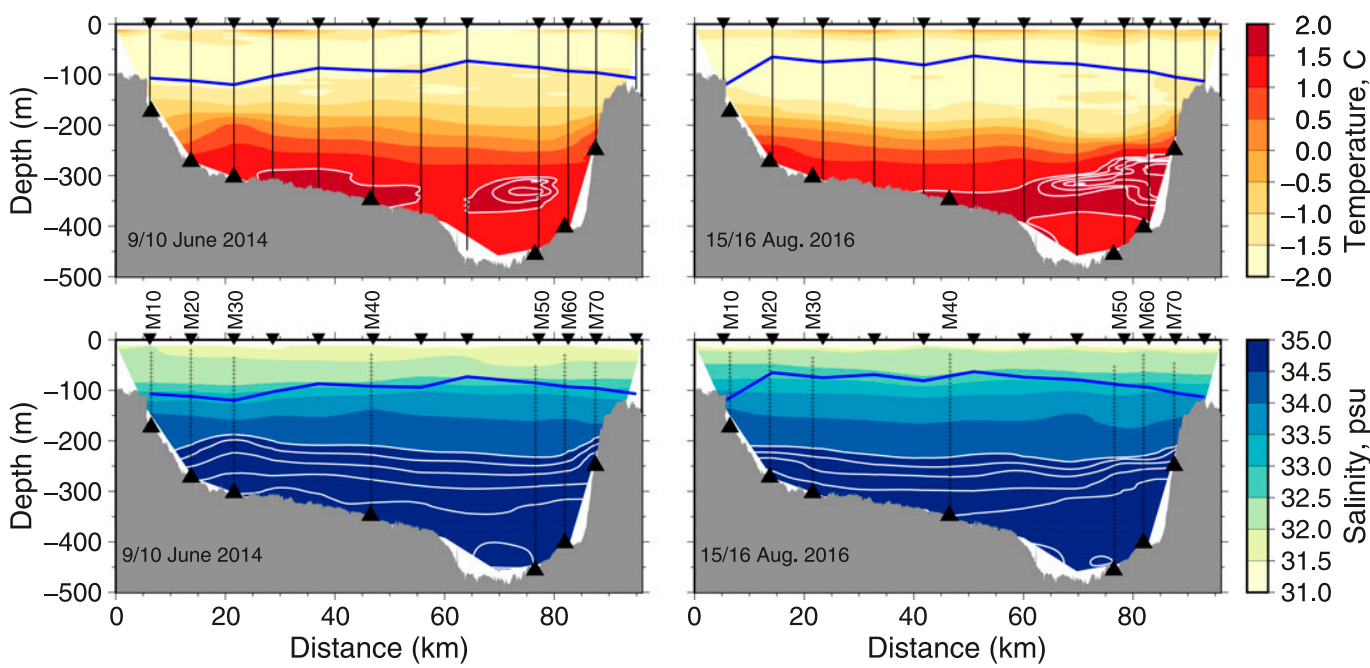

FIG. 4. (left) Potential temperature and salinity across Norske Trough on 9-10 Jun 2014 with seven 2014-16 ADCP mooring deployment locations (bottom triangles) labeled M10 through M70. CTD stations are small triangles at the surface. View is along the canyon toward the coast. White contour lines near the bottom are $0.1 \mathrm{psu}$ and $0.1^{\circ} \mathrm{C}$ for salinity and potential temperature, respectively. The temperature maximum of $1.7^{\circ} \mathrm{C}$ occurs at $340-\mathrm{m}$ depth near $75 \mathrm{~km}$. The blue line indicates maximal vertical stratification (stability frequency maximum) below 50-m depth. (right) As in the left panels, but for 15-16 Aug 2016. The temperature maximum of $1.9^{\circ} \mathrm{C}$ occurs at $290-\mathrm{m}$ depth near $85 \mathrm{~km}$.

depth relative to a weaker flow at the surface. Temperature time series within about $3 \mathrm{~m}$ off the bottom (not shown) indicate that these patterns persist throughout the year, that is, seasonal variations are small and negligible.

\section{Ocean circulation}

\section{a. Mean flow and volume flux}

The data from this array of seven ocean current moorings describe a jet over the northeastern slope of
Norske Trough whose depth- and time-averaged representation we show in Fig. 3 and list with uncertainties in Table 2. Figure 5 shows the record-mean velocity along the canyon for the three northeastern mooring sites M50, M60, and M70. The flow constitutes a 10-kmwide bottom intensified jet toward coastal glaciers in the northwest. The velocity maximum exceeds $0.08 \mathrm{~m} \mathrm{~s}^{-1}$ near 300-m depth and diminishes toward both the surface and the channel center (Fig. 5). This bottomintensified flow is the main circulation feature to

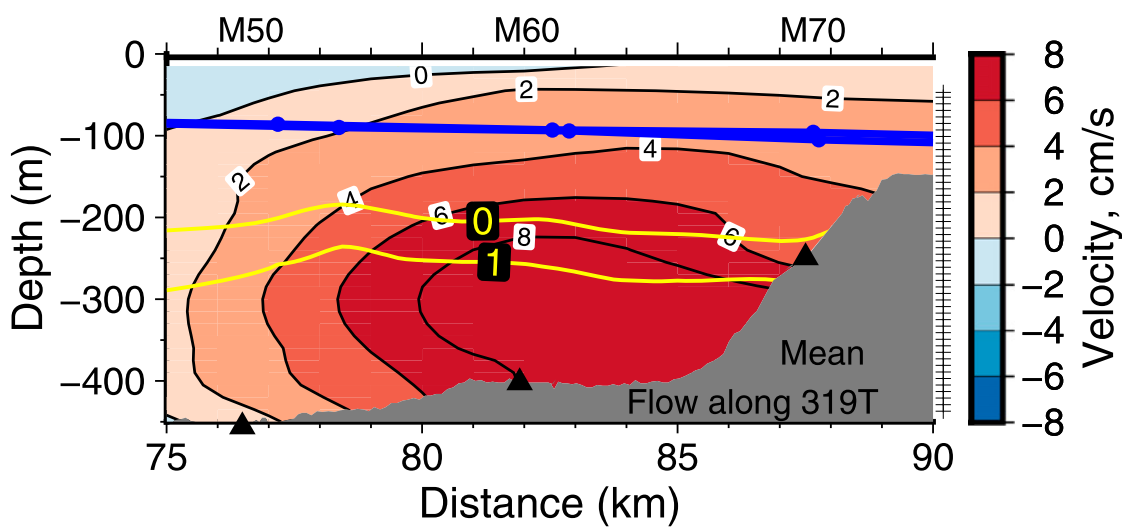

FIG. 5. Velocity across the northeastern slope of Norske Trough from 2014 to 2016 ADCP moorings. View is along the canyon toward the coastal glaciers. Three symbols near bottom are locations of bottom-mounted ADCPs at M50, M60, and M70. Red colors indicate flow into the page toward the northwest $\left(319^{\circ} \mathrm{T}\right)$. Tick marks on the right axis indicate vertical bin locations. Two temperature contours are shown in yellow $\left(0^{\circ}\right.$ and $\left.1^{\circ} \mathrm{C}\right)$ from a June $2014 \mathrm{CTD}$ survey shown in Fig. 4, while the blue contour and symbols identify the depth of maximal stability frequency to represent the pycnocline. 


\section{$2014 \quad 2015$}

J J A S O N D J F MA M J A S O N D F MA M J J A

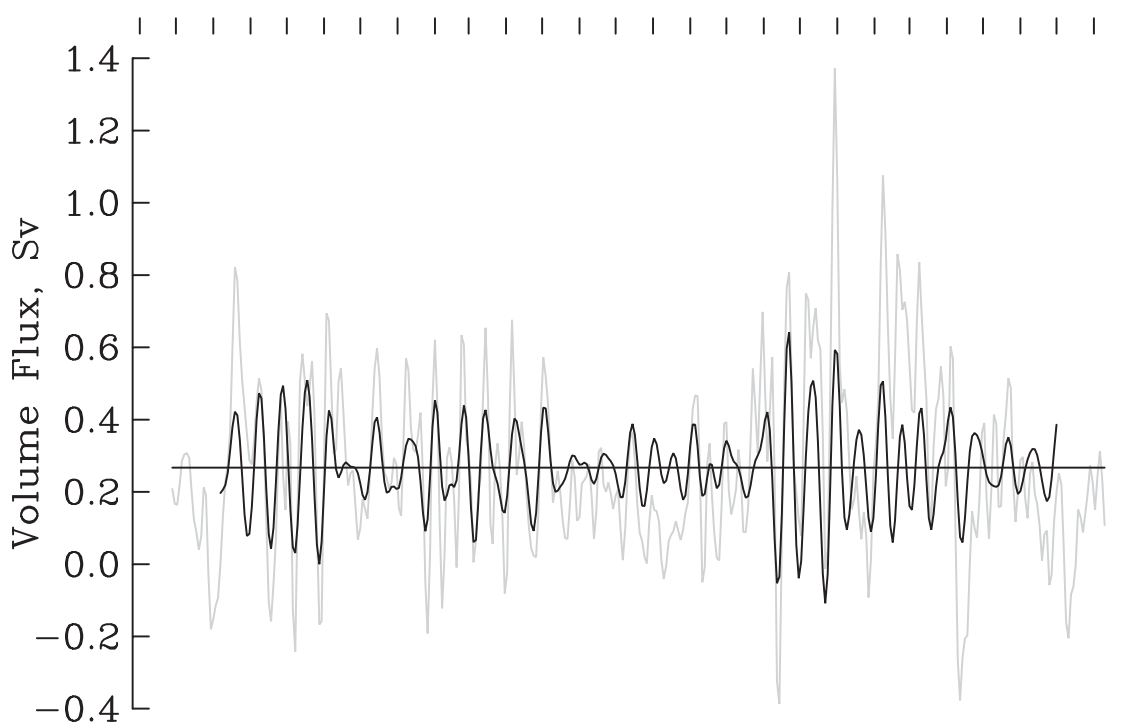

FIG. 6. Time series of ocean volume flux below 150-m depth. Flux data are bandpass filtered (19-21 days) to emphasize low-frequency (Rossby wave) variability. The subtidal flux is shown in light gray while the time mean flux is the horizontal line at $Q_{0}=0.27 \pm 0.06 \mathrm{~Sv}$.

dominate both the time mean and the time-domain variability.

Spatial patterns coherent to all records from all seven mooring locations reveal that more than $36 \%$ of the total variance is contained within the principal pattern (not shown) that has its maximal value $150 \mathrm{~m}$ below the surface at mooring sites M50, M60, and M70 over the northeastern slope of Norske Trough. The data from the southwestern four moorings contribute little to this mode. We subsequently focus on the spatial and temporal variability of this northeastern slope current that advects warm waters of Atlantic origin across the continental shelf of northeast Greenland.

Figure 6 shows the volume flux $Q(t)$ of Atlantic influenced waters that we define as those with salinities larger than $34 \mathrm{psu}$. This isohaline is almost level across the section at 150-m depth (Fig, 4). Estimating volume transport, we generate regular grids of daily velocity $u(x, z, t)$ that we integrate vertically from the bottom at $H(x)$ to 150 -m depth and horizontally from $x_{1}=75$ to $x_{2}=90 \mathrm{~km}$, for example,

$$
Q(t)=\int_{x_{1}}^{x_{2}} \int_{-H(x)}^{-150} u(x, z, t) d z d x .
$$

The mean volume flux $Q_{0}$ becomes $0.27 \pm 0.06 \mathrm{~Sv}$ $\left(1 \mathrm{~Sv} \equiv 10^{6} \mathrm{~m}^{3} \mathrm{~s}^{-1}\right)$. Uncertainties are $95 \%$ confidence limits assuming an integral time scale of about 11 days. Also shown in Fig. 6 are the 2-day low-pass and 19-21day bandpass filtered data. Values including the temporal mean range from -0.4 to $+1.4 \mathrm{~Sv}$ for the low-pass and from +0.0 to $+0.6 \mathrm{~Sv}$ for the bandpass data. Positive flux is to the northwest toward coastal glaciers. Next we detail vertical and lateral structures of this along-slope current.

\section{b. Vertical velocity variations}

In Fig. 7 we show current vector time series at the core of the slope jet at five selected depths between 39 and $335 \mathrm{~m}$ below the generally ice-covered surface. The flow below $150-\mathrm{m}$ depth is remarkably steady and to the northwest toward the coast. Current reversals are few and short-lived. Seasonal variations emerge and their amplitudes determined from a harmonic analysis (not shown) increase from less than $0.015 \mathrm{~m} \mathrm{~s}^{-1}$ near the bottom to almost $0.06 \mathrm{~m} \mathrm{~s}^{-1}$ at $143 \mathrm{~m}$ (not shown). Strongest seasonal flow to the north occurs in December and January and weaker flow in June and July. Both the time mean flow and variations align along an axis close to $319^{\circ}$ clockwise from true north that we subsequently select as the along-canyon direction. We will next quantify mean, seasonal, and residual subinertial currents.

Figure 8 depicts the record-mean vertical profile at M60 separated into along-canyon and across-canyon components. Within about $150 \mathrm{~m}$ of the surface both 


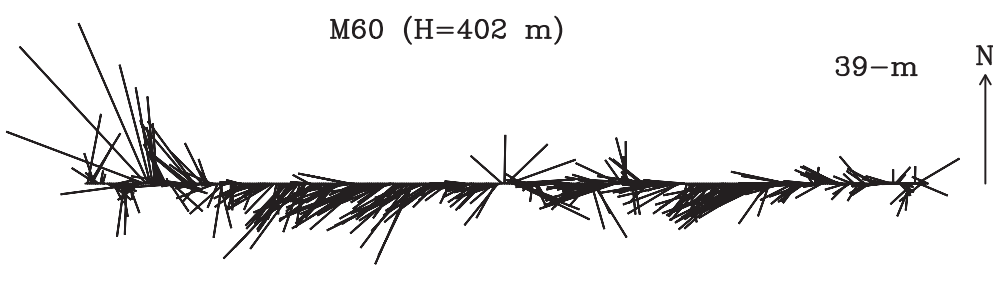

$95-\mathrm{m}$
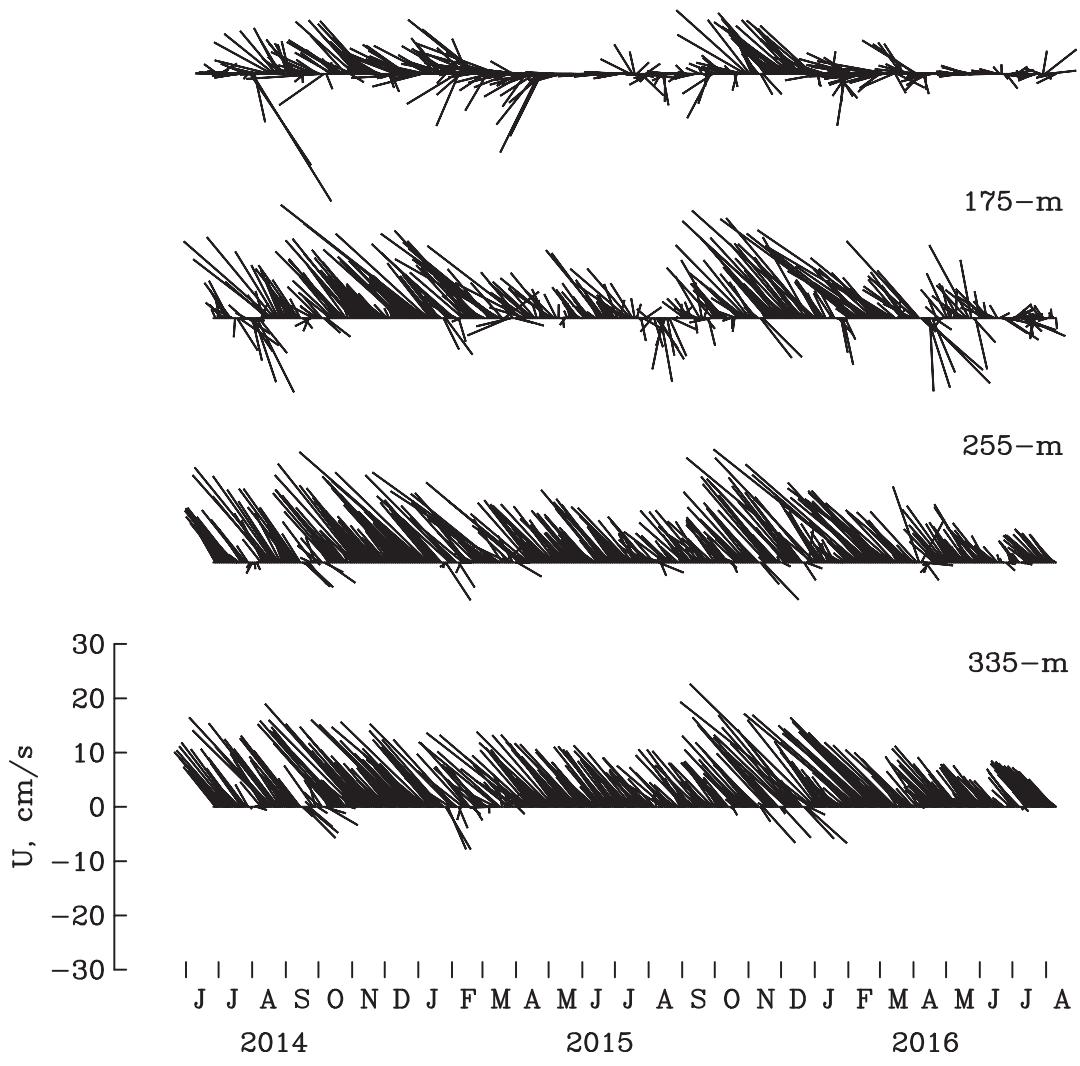

FIG. 7. Time series of ocean current vectors at selected depths at the center of the jet (M60) over the northeastern canyon wall. Note the bottom-intensified flow. A Lanczos low-pass filter removes variability at time scales smaller than 5 days to emphasize mean and low-frequency variability.

along- and across-channel speeds are about $0.04 \mathrm{~m} \mathrm{~s}^{-1}$ with uncertainties of about $0.02 \mathrm{~m} \mathrm{~s}^{-1}$. The positive acrosschannel velocity is a flow to the west, which is dynamically consistent with the geostrophic adjustment to a frictional Ekman-like response to winds generally blowing from the north, for example, Fig. 2b. At depths below $150 \mathrm{~m}$ the across-channel velocity component vanishes while the along-channel component increases to a maximum of $0.10 \pm 0.01 \mathrm{~m} \mathrm{~s}^{-1}$ near 325-m depths. Below this depth currents along the topography reduce toward the bottom with a small across-channel component downslope that is dynamically consistent with a frictional Ekman-like response also, but the downslope flow here is imposed by the along-channel current above.
The temperature structure on both 10 June 2014 and 16 August 2016 reveal 150 -m-thick surface layers that consists of uniformly cold $\left(-1.6^{\circ} \mathrm{C}\right)$ waters where salinity stratifies the water (Fig. 4) and the time-mean flow is dominantly across topography. Below this halocline layer we find a thermocline layer between 150- and 300-m depth that has a constant temperature gradient of about $2.8^{\circ} \mathrm{C}$ per $150 \mathrm{~m}$. Vertical current shear is largest within this thermocline layer as we approach both the vertical temperature and velocity maximum below $300-\mathrm{m}$ depth. Here the waters are uniformly warm $\left(+1.3^{\circ} \mathrm{C}\right)$ and salty $(34.8 \mathrm{psu})$. The core of the bottomintensified jet thus advects heat from Fram Strait across the shelf toward the coast. 


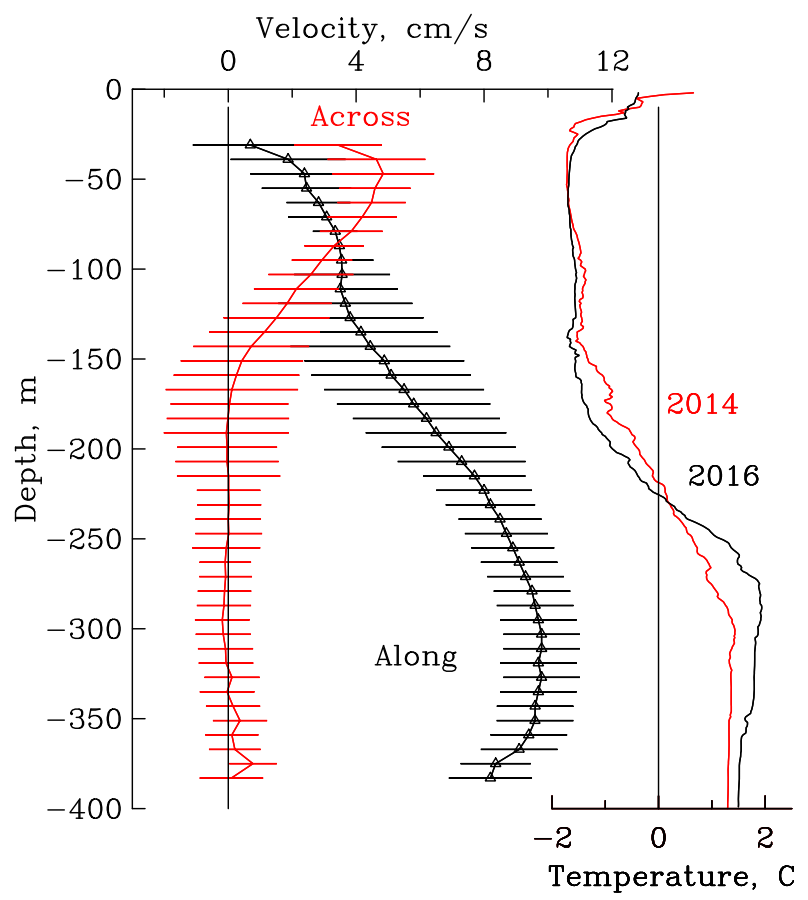

FIG. 8. Velocity components along (black symbols) and across (red line) Norske Trough at M60 $\left(319^{\circ} \mathrm{T}\right)$ with $95 \%$ uncertainty of speed and direction. Temperature profiles at the location are shown in the right panel from June 2014 in red and August 2016 in black

\section{c. Time-dependent currents}

Removing the mean currents at each depth, we next describe principal patterns of variability in the alongchannel direction with empirical orthogonal functions (EOF) as these constitute the most efficient presentation of variability (Davis 1976). More specifically, EOF analyses quantify the distribution of variance among a set of mutually uncorrelated patterns in space and how these spatial patterns vary in time. We decompose 45 time series of along-channel velocity observations $u(z, t)$ at M60 (see Fig. 8 for locations) into $M=$ 45 modes via the linear transformation

$$
u\left(z_{i}, t\right)=\sum_{n=1}^{M} A_{n}(t) \theta_{n}\left(z_{i}\right)
$$

where $A_{n}(t)$ and $\theta_{n}\left(z_{i}\right)$ denote the temporal amplitude and vertical pattern of the $n$th EOF mode, respectively. We scale $A_{n}(t)$ and $\theta_{n}\left(z_{i}\right)$ such that $A_{n}(t)$ is dimensionless with variance 1 and $\theta_{n}\left(z_{i}\right)$ has units of centimeters per second $\left(\mathrm{cm} \mathrm{s}^{-1}\right)$. Appendix B explains the details.

From 45 distinct eigenvectors $\boldsymbol{\theta}_{n}(z)$ we find that $\boldsymbol{\theta}_{1}, \boldsymbol{\theta}_{2}$, and $\boldsymbol{\theta}_{3}$ dominate as they explain about $95 \%$ of the total velocity variance. Figure 9 shows these three dominant modes, and we limit our discussion to them. The first mode explains $77 \%$ of the variance, and its vertical structure resembles the time-mean bottom-intensified flow. This first EOF has a peak velocity of about $0.08 \mathrm{~m} \mathrm{~s}^{-1}$ at $180-\mathrm{m}$ depth with strong vertical shear toward zero above this depth and little shear toward the bottom (Fig. 9a). The flow within $100 \mathrm{~m}$ of the surface does not contribute much to this EOF which contrasts with the next two modes. Mode 2 reflects a balanced exchange flow for which surface and bottom currents are anticorrelated, that is, a flow toward the coast at the surface coincides with a bottom flow in the opposite direction and vice versa. This exchange mode captures about $15 \%$ of the total variance. An intensified surface flow in the upper $100 \mathrm{~m}$ of the water column is described by mode 3 , however, this mode contains only $4 \%$ of the total variance and thus can be neglected along with higher modes not shown.

We note that the time scales of the bottom-intensified flow $A_{1}$, the exchange flow $A_{2}$, and the surface-intensified flow $A_{3}$ differ. Figure 10 presents autospectral estimates of the temporal variations $A_{1}(t)$ and $A_{2}(t)$ that for $A_{1}$ reveal three clear spectral peaks near 6-, 11-, and 20-day periodicities. Signals with these time scales each contain more than $15 \%$ of the total variance and represent the principal time scales at which the bottom-intensified jet varies about its mean. The second mode $A_{2}$ has a single distinct peak near 20 days and contains most of its variance at periodicities larger than 60 days $(0.016$ cycles per day or cpd below). We speculate that seasonally variable sea ice and winds causes these variations expressed in $A_{2}$ and $\boldsymbol{\theta}_{2}$. Identical analyses for the data from adjacent upslope and downslope moorings M70 and M50 reveal similar results (not shown). We thus find similar vertical flow structures and time scales of variability from EOF analyses. We next investigate the across-canyon correlation of these flow structures with a linear systems analysis that will reveal wavelike properties of observed current fluctuations.

\section{d. Topographic Rossby wave}

We estimate spectral properties from 2-yr time series at M50 and M60 at 309- and 303-m depth, respectively, because these two time series are both within the core of the warm subsurface jet (Fig. 5). A frequency-domain linear system $Y=H \times X$ uses M60 as input $X$ with an autospectrum $G_{x x}$ and M50 as output $Y$ with an autospectrum $G_{y y}$. The autospectra are real functions of frequency $f$ that estimate the kinetic energy per frequency interval. In contrast the transfer function $H=|H| e^{-j \Theta_{x y}}$ is complex and thus carries both amplitude and phase information. The phase is estimated from the complex cross-spectrum $G_{x y}=\left|G_{x y}\right| e^{-j \Theta_{x y}}$ (Bendat and Piersol 1986). We use $G_{x y}$ to aid in the interpretation 
(a) $76.9 \%$

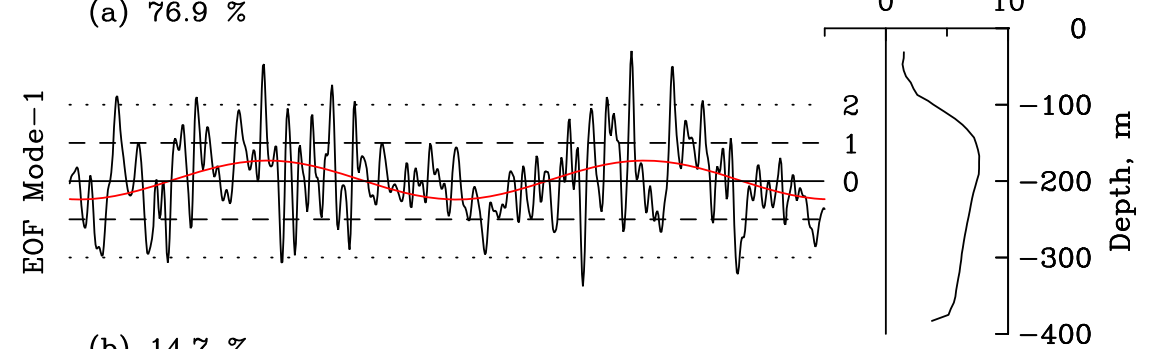

(b) $14.7 \%$
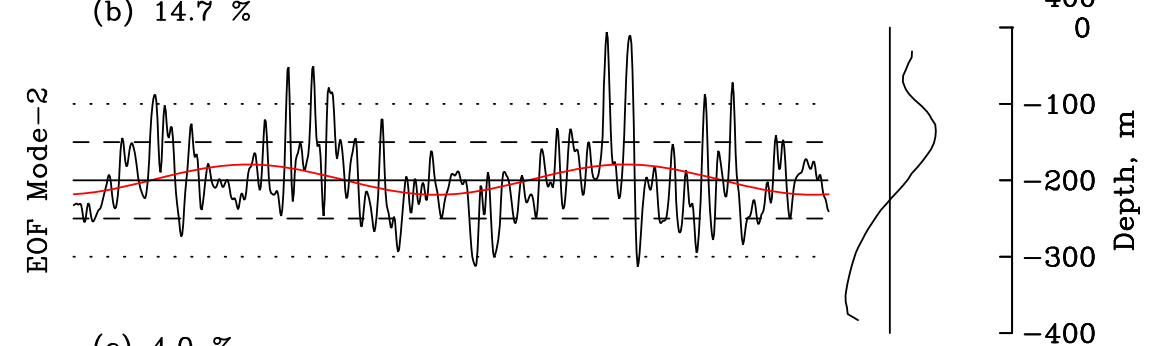

(c) $4.0 \%$
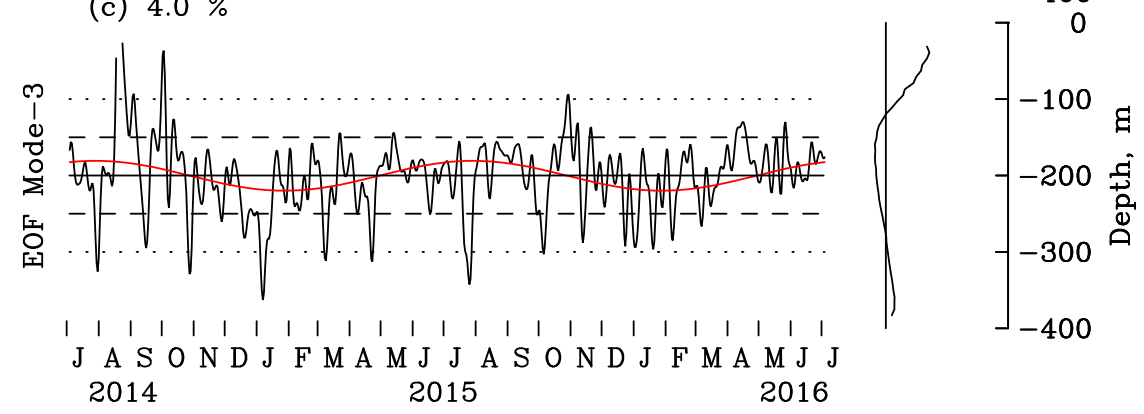
2014 2015

2016

FIG. 9. Temporal and vertical variability at the center of the inflowing jet (M60) organized by empirical orthogonal analysis. Time series are in unitless standard deviations while vertical patterns have units of centimeters per second. The variance explained by each mode is listed. Red lines fit an annual cycle to the time series.

of oscillatory motions with enhanced kinetic energies near periodicities of 20,11, and 6 days (Fig. 10). More specifically, across-slope phase relations and principal axes of variations implicate topographic Rossby waves (Pickart and Watts 1990) as a possible explanation of the observed current oscillations. We discuss wave properties below after we quantify the phase propagation across the slope of signals that are coherent at M60 and M50.

Figure 11 shows the phase $\Theta_{x y}(f)$ for $f \leq 0.3 \mathrm{cpd}$. We find $\Theta_{x y}>0$, that is, oscillations occur first at M60 before they appear at M50. For example, at $0.05 \mathrm{cpd}$, a phase $\Theta_{x y}=30^{\circ}$ indicates that a signal takes $40 \mathrm{~h}$ to reach M50 from M60. This corresponds to phase speed $c_{p}=(1 / T)\left(360 / \Theta_{x y}\right)(\Delta s / \cos \Delta)=3.2 \mathrm{~km} \mathrm{day}^{-1}$ for a wave with period $T=20$ days, site separation $\Delta s=5.3 \mathrm{~km}$, and the angle $\Delta=1^{\circ}$ between the mooring line (39T) and the orientation of the wavenumber vector (Pickart and Watts 1990). The implied wavelength is $\lambda=c_{p} T=63 \mathrm{~km}$.

How much of the variance of this 63-km across-slope scale at location M60 relates in this "linear wave fashion" to the variance at location M50? Figure 11 suggests about $70 \%$, because the coherence $\Gamma^{2}=\left|G_{x y}\right|^{2} /\left(G_{x x} G_{y y}\right)$ estimates the fraction of the input variance related linearly to the output variance. The coherence $\Gamma^{2}$ reaches almost 0.7 at the relevant frequencies between 0.01 and $0.3 \mathrm{cpd}$ (Fig. 11). This value is far above the $95 \%$ confidence level of 0.15 . We next compare these coherent observations with predictions from linear wave theory.

The dispersion relation of linear internal waves on a rotating plane in the presence of a bottom slope relates the wave frequency $\omega=2 \pi / T$ to the wavenumber $K=2 \pi / \lambda$ as

$$
\omega(K)=-\frac{N \alpha \sin \phi}{\tanh \left(K L_{D}\right)},
$$

which defines topographic Rossby waves (Gill 1982; Rhines 1970). Here $N$ is the stability frequency $\left(0.005 \mathrm{~s}^{-1}\right)$, $D$ is a vertical scale of motion $(400 \mathrm{~m}), \alpha$ is the bottom slope (0.03), and $\sin \phi=k / K$ indicates the orientation of the wavenumber vector $\mathbf{k}=(k, l)$ with magnitude 


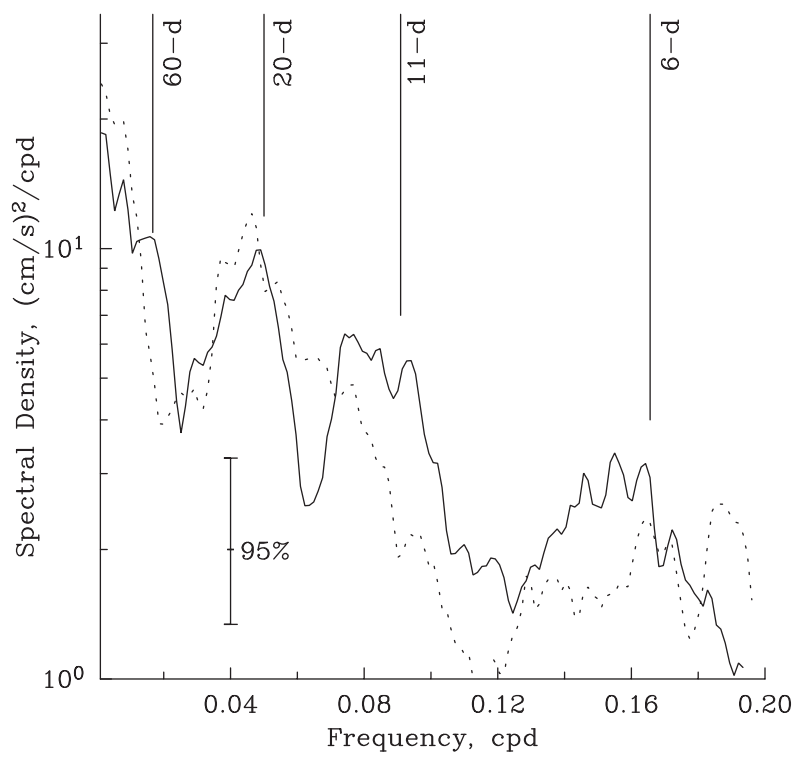

FIG. 10. Distribution of variance with frequency for the EOF1 (solid line) and EOF2 (dotted line) shown in Figs. 9a and 9b, respectively.

$K=\sqrt{\left(k^{2}+l^{2}\right)}$ and components $k$ along and 1 across the bottom topography. The parameter $L_{D}=N D / f_{0}=$ $14 \mathrm{~km}$ is the internal Rossby radius of deformation and $f_{0}$ is the local Coriolis parameter $\left(0.00014 \mathrm{~s}^{-1}\right)$.

The waves are transverse, that is, they have $\mathbf{k} \cdot \mathbf{u}=0$ where $\mathbf{u}$ is flow velocity associated with the wave (Rhines 1970). Thus, we can interpret the angle $\phi+\pi / 2$ as the orientation of the current ellipse (Pickart and Watts 1990; Harden and Pickart 2018). The minus sign in Eq. (4) indicates that waves propagate with shallower water to the right in the Northern Hemisphere, that is, the wave moves its perturbations along $\mathbf{k}$ across topography from shallow to deep water. The restoring force is the vortex tube stretching over a sloping bottom in the presence of both rotation and stratification (Zhao and Timmermans 2018).

For the observed wavelength of $63 \mathrm{~km}$ and period of 20 days the dispersion relation Eq. (4) predicts the angle $\phi=179^{\circ}$ that is the direction of the phase velocity relative to upslope. We can compare this prediction against the orientation of the observed current ellipse at this frequency, because the wavenumber is always perpendicular to the current vector. We estimate current ellipses from bandpass filtered velocity data and list both observed and estimated wave properties in Table 3 for waves with periods near 20 , 11 , and 6 days.

Figure 12 shows our coordinate system that we orient along $(x)$ and across $(y)$ the local topography. We also show current ellipses near 220-m depth at three locations across the slope. The deviation of the semimajor axis of length $R_{\text {maj }}$ from the along-slope direction constitutes the observational estimate of the angle $\phi_{\mathrm{obs}}$ measured from the across-slope direction. Analytical predictions of $\phi$ from the dispersion relation, for example, $\phi_{\text {ana }}$ agree with those derived directly from the observed, bandpassed flow field, for example, $\phi_{\mathrm{obs}}$ (Table 3). The phase velocity vector is almost perpendicular to the topography, that is, the principal axis of current oscillations is almost along topography. This is a characteristic of short and strongly stratified Rossby waves where $\tanh \left(K L_{D}\right) \sim 1$ (Pickart and Watts 1990). The bottom slope traps wave energy, that is, velocity variance near the bottom exceeds that near the surface. Velocity profiles vary as $\cosh (\mu z)$ in the vertical $z$ coordinate (Rhines 1970) where $\mu^{-1}=D /\left(K L_{D}\right)$ ranges from about 200 to $300 \mathrm{~m}$ for our waves (Table 3 ). Furthermore, we find, as expected from linear wave theory, that the angles $\phi_{\text {obs }}=\phi_{\text {obs }}(\omega)$ rotate clockwise with increasing $\omega$, that is, higher-frequency motions propagate perturbations with more of an along-slope component than lower frequency motions. We note, however, that all these angles are small as the alongslope component of the wavenumber $k$ is much smaller than the across-slope component 1 , that is, $k \ll l$.

\section{Forcing}

For stratified topographic Rossby waves with $K L_{D} \gg 1$ the dispersion relation simplifies to $\omega(K) \approx-N \alpha \sin \phi$. From this approximation we find the group velocity vector

$$
\mathbf{c}_{g}=\left(\partial_{k} \omega, \partial_{l} \omega\right)=c_{0}(-\cos \phi, \sin \phi),
$$

where $c_{0}=(N \alpha \cos \phi / K)$ and $\cos \phi=l / K$ (Harden and Pickart 2018). Figure 12 shows $\mathbf{c}_{g}$ for the 19.3 day oscillation. The speed of the energy flux vector $\mathbf{c}_{g}$ is $63 \mathrm{~km} \mathrm{day}^{-1}$ and it is directed into the Norske Trough system from offshore Fram Strait toward the coastal glaciers in the northwest. Hence, we must seek the energy source for our observed wave motions to the southeast of our study area where the trough system broadens and merges with the slope of the outer continental shelf and Fram Strait. Here the ice cover is mobile all year and allows for efficient momentum transfer from the atmosphere to the ocean.

Our observed topographic Rossby waves depend on vertical density stratification $N$ and a sloping bottom $\alpha$, for example, $\omega=\omega(N, \alpha)$ that both provide the restoring mechanism for wave perturbations via vortex tube stretching in a baroclinic fluid. The curl of the surface wind stress perturbs the density field via an Ekman pumping velocity $w_{e}$ (Gill 1982) 

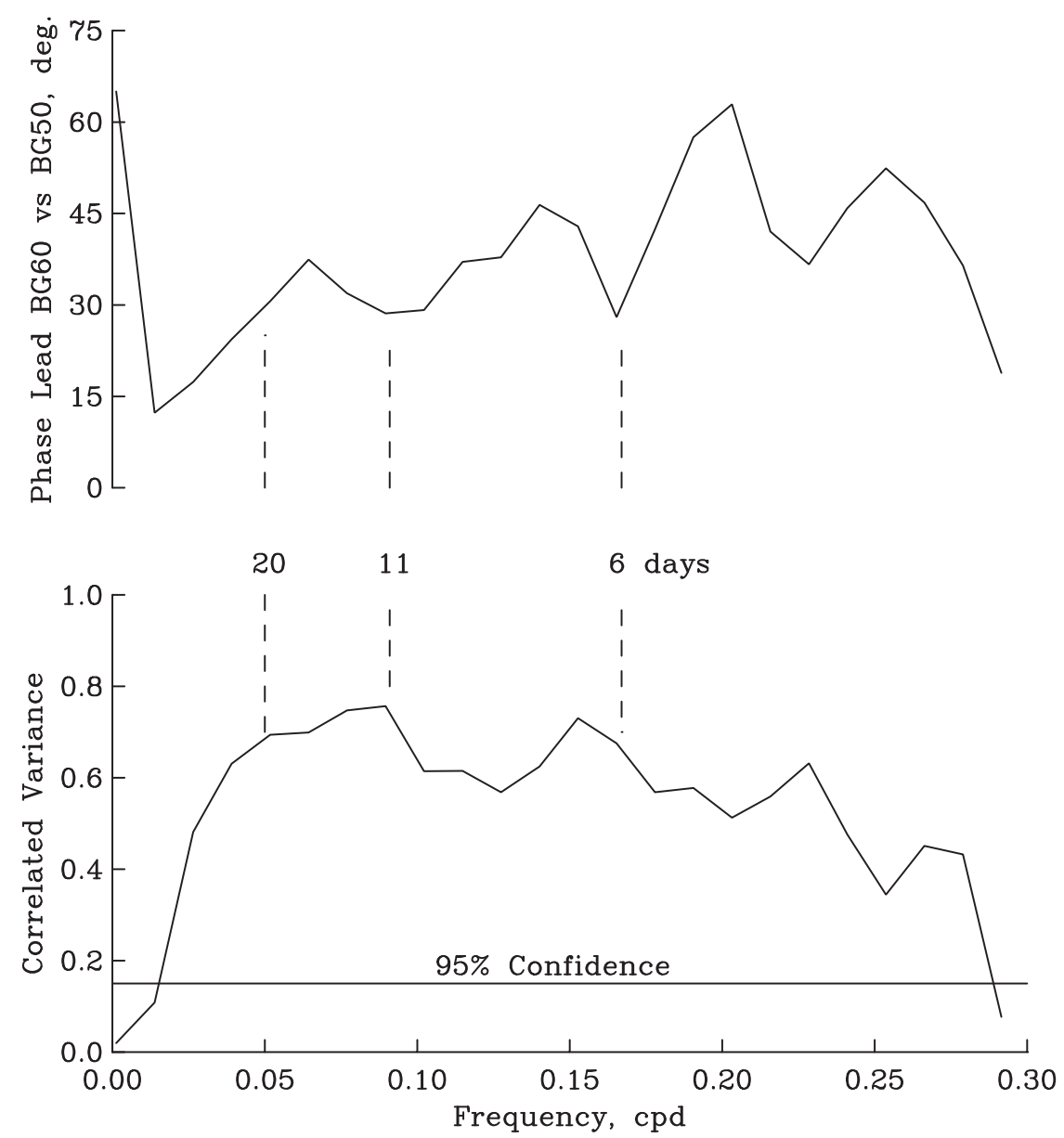

FIG. 11. (bottom) Coherence and (top) phase of along-canyon flows at M60 (303 m) and M50 $(309 \mathrm{~m})$ with frequency. Positive phase indicates correlated signals appear first at BG60 to propagate offshore to M50. Coherence estimates above 0.15 are significantly different from zero at $95 \%$ confidence.

$$
w_{e}=\left(\partial_{x} \tau^{(y)}-\partial_{y} \tau^{(x)}\right) /\left(\rho_{0} f_{0}\right)
$$

and this density perturbation, we postulate, then travels as the topographic Rossby wave whose properties we list in Table 3. Appendix $\mathrm{C}$ describes details of our wind stress estimation in ice-covered seas that use ERA-Interim wind and SSM/I sea ice products at daily and $25-\mathrm{km}$ scales.

Figure 13 shows a snapshot of the spatial wind variability during a particular strong event on 17 December of 2015 when cyclonic winds reach $20 \mathrm{~m} \mathrm{~s}^{-1}$ in Fram Strait just seaward of the 1000-m isobath. In contrast,

TABLE 3. Estimated topographic Rossby wave properties. The wave period $T$ is estimated from the frequency-domain location of kinetic energy maxima. Cross-spectra estimate phase lags at these periods are used to estimate phase speed $C_{p}$, group velocity $C_{g}$, wavelength $\lambda$, and, from the dispersion relation, the orientation $\phi_{\text {ana }}$ of the wavenumber vector relative to the upslope direction (38T). Positive angles are counterclockwise. A second independent estimate of this angle is $\phi_{\text {obs }}$, which is derived from bandpassedfiltered, time-domain estimation of the ocean current ellipse orientations. Additional ellipse parameters are semimajor $R_{\text {maj }}$ and minor $R_{\min }$ axes.

\begin{tabular}{cccccccrrr}
\hline \hline $\begin{array}{c}\text { Period } T \\
(\text { days })\end{array}$ & $\begin{array}{c}\Gamma^{2} \\
(-)\end{array}$ & $\begin{array}{c}C_{p} \\
\left(\mathrm{~km} \mathrm{day}^{-1}\right)\end{array}$ & $\begin{array}{c}C_{g} \\
\left(\mathrm{~km} \mathrm{day}^{-1}\right)\end{array}$ & $\begin{array}{c}\lambda \\
(\mathrm{km})\end{array}$ & $\begin{array}{c}\text { Decay } \mu^{-1} \\
(\mathrm{~m})\end{array}$ & $\begin{array}{c}\phi_{\text {ana }} \\
\left({ }^{\circ}\right)\end{array}$ & $\begin{array}{c}\phi_{\text {obs }} \\
\left({ }^{\circ}\right)\end{array}$ & $\begin{array}{c}R_{\text {maj }} / R_{\text {min }} \\
(-)\end{array}$ & $\begin{array}{c}\text { Scale } \\
(\text { days })\end{array}$ \\
\hline 6.5 & 0.73 & 6.8 & 44 & 93 & 197 & 175.9 & 175.9 & 6 \\
11.2 & 0.76 & 6.0 & 67 & 140 & 298 & 177.8 & 177.0 & 8 & $7-7$ \\
19.3 & 0.69 & 3.2 & 63 & 131 & 280 & 178.7 & 177.5 & 8 & $14-28$ \\
\hline
\end{tabular}




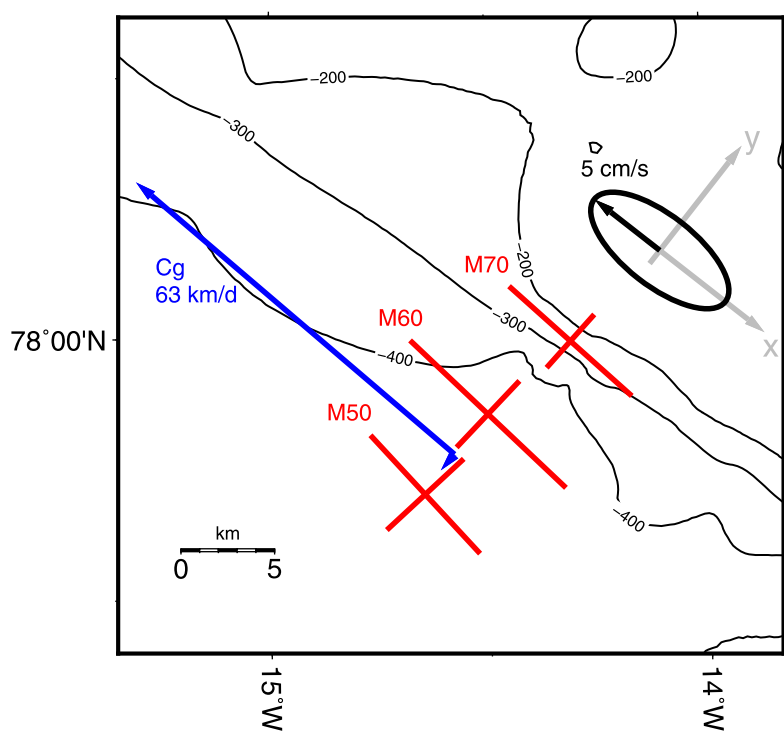

FIG. 12. Ocean current ellipses (red) at 231, 215, and $237 \mathrm{~m}$ at mooring locations M50, M60, and M70, respectively. Along-slope $(x)$ and across-slope $(y)$ coordinate axes are shown (gray) along with a scale for ellipses (black). Group and phase velocity vectors are shown in blue for a topographic Rossby wave with a period of 19.3 days (Table 3 ).

near our mooring location wind speeds are less than $5 \mathrm{~m} \mathrm{~s}^{-1}$. The vertical upwelling is maximal near the continental slope while it is close to zero at our mooring site. Bottom-intensified ocean currents at the time are two standard deviations above the mean as expressed in the first EOF at M60 (Fig. 9).

Searching more systematically for a source location of the topographic Rossby wave generation, we correlate our ocean current time series with Ekman pumping time series at all locations. The correlation is done for signals in the narrow $[19,21]$ day band in the frequency domain where we find enhanced kinetic energy (Fig. 10). The correlation then becomes $\Gamma^{2}(x, y)$ for $\omega=$ const. that we map in Fig. 14. While statistically significant coherences $\Gamma^{2}$ are found scattered throughout the study area, we indeed find the largest coherence $\Gamma^{2}>0.4$ in a 100-km-long and $50-\mathrm{km}$-wide band over the shelf break near the 1000-m isobath where Norske Trough connects to Fram Strait. We will next quantify the distribution of Ekman pumping and how it correlates with velocity fluctuations that include our topographic Rossby waves.

The time series of $w_{e}\left(x=8^{\circ} \mathrm{W}, y=76.5^{\circ} \mathrm{N}, t\right)$ contains enhanced variance at periodicities near $20,11,6$, and 4.5 days (Fig. 15). The spectral peaks are similar to those we find in the spectra of bottom currents in Norske Trough (Fig. 10) that correlate across the slope with $\Gamma^{2}$ $\sim 0.7$ (Fig. 11). Estimating the coherence of bottom currents in Norske Trough and Ekman pumping near

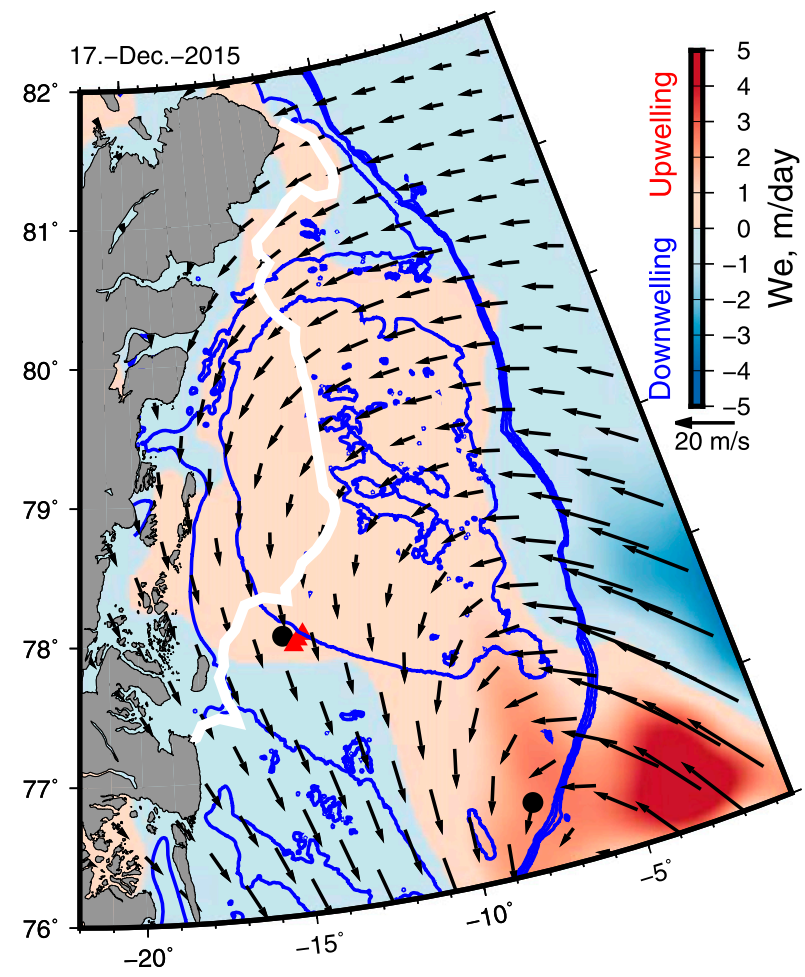

FIG. 13. Surface wind vectors on 17 Dec 2015 with Ekman pumping velocities (color) estimated from the curl of the wind stress (ERA-Interim). Bottom topography at 250, 1000, 1100, and $1200 \mathrm{~m}$ is indicated by blue contours, and red triangles show ocean mooring locations while black circles indicate locations of Ekman pumping velocity time series shown in Figs. 15 and 16.

the shelf break about $180 \mathrm{~km}$ to the east, we find that the correlated variance at the 20 -day time scale exceeds $40 \%$. This is well above the $99 \%$ confidence level $\Gamma_{99}^{2}=0.23$ for 40 degrees of freedom. Note also that the correlation of the signals with frequencies between 0.15 and $0.07 \mathrm{cpd}$ (7-14 days) falls below this significance level. Currents at these frequencies thus are not correlated to Ekman pumping at a $99 \%$ level of confidence. Hence, we suggest that only low-frequency bottom currents in Norske Trough with periods near 19-21 and 5-6 days are forced remotely by the wind stress curl near sloping topography of Fram Strait. The kinetic energy generated by the wind stress curl propagates with the group velocity of a baroclinic Rossby wave along the sloping topography to cause along-slope velocity oscillations at 20-day periodicities.

Furthermore, the correlated variance suggests a linear input-output system: bottom currents lag the Ekman pumping by about $70^{\circ}$ or about 4 days at a 20 -day period. This lag translates to a speed of $45 \mathrm{~km} \mathrm{day}^{-1}$ for the $180-\mathrm{km}$ distance between these locations. Visualizing this phase lag, we show in Fig. 16 bandpass-filtered time series of Ekman pumping at two select locations (shown 


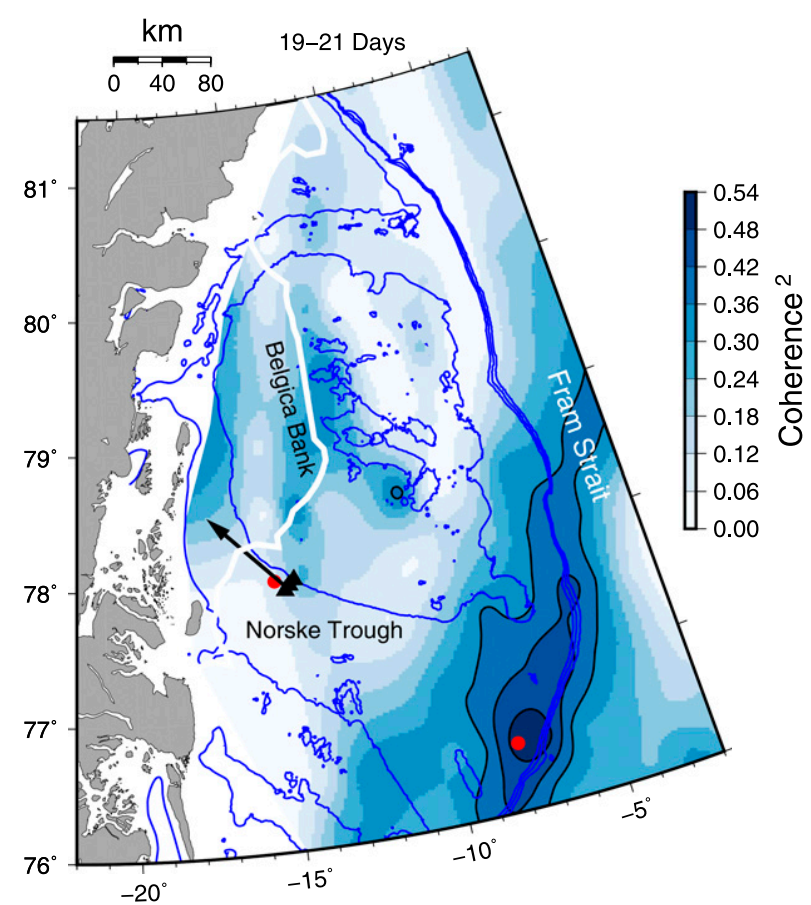

FIG. 14. Coherence $\Gamma^{2}$ between 786-day-long time series of Ekman pumping velocities and near-bottom currents along the slope of Norske Trough in the [19,21] day frequency band. Bottom topography at 250,1000,1100, and $1200 \mathrm{~m}$ is indicated by blue contours, and black triangles show locations of ocean moorings. Black contours highlight the topographic Rossby wave source region with $\Gamma^{2}$ of $0.36,0.42$, and 0.48 ; the arrow indicates the direction of wave group velocity; and red dots show location of reference time series shown in Fig. 16.

in Fig. 13) that we each overlay with similar bandpassfiltered bottom velocity at M60. Prominent bottom velocity oscillations with amplitudes near $0.1 \mathrm{~m} \mathrm{~s}^{-1}$ emerge in November of 2015 and persist through February of 2016. The visual correlation is strong at the shelfbreak for $w_{e}$ at $7^{\circ} \mathrm{W}$ (bottom panel of Fig. 16) while it is weak at the mooring locations near $15^{\circ} \mathrm{W}$ (top panel of Fig. 16). The winter 2015/16 Ekman pumping near the 1000-m isobath of Fram Strait has an amplitude of about $0.4 \mathrm{~m} \mathrm{day}^{-1}$ from which our linear system analysis gives a gain (not shown) of $19 \mathrm{~cm} \mathrm{~s}^{-1}\left(\mathrm{~m} \mathrm{day}^{-1}\right)^{-1}$ for both the 20- and 6-day oscillations. Positive $w_{e}$ (downwelling) in Fram Strait leads negative along-slope bottom velocities (landward) in Norske Trough. Note, however, that we present gain, phase, and coherence in the frequency domain and we thus weight all data from the entire 945-daylong time series equally.

\section{Discussion and conclusions}

We introduced ocean current time series from a single array of seven moorings that each contained a vertically profiling ADCP that returned data from June 2014 through August 2016. The data described the flow field within an 80-km-wide canyon off northeast Greenland that connects Fram Strait offshore with tidewater glaciers inshore. The array sampled a single section across Norske Trough with distinct circulations on each side of the sloping canyon. We focused on a bottom-intensified jet over the northeastern slope that advects warm waters of Atlantic origin from Fram Strait across the continental shelf via Norske Trough.

Subtidal flows exceed $0.2 \mathrm{~m} \mathrm{~s}^{-1}$ and are remarkably steady especially below $150-\mathrm{m}$ depth where they flux a volume of $0.27 \pm 0.06 \mathrm{~Sv}$ toward coastal glaciers. Currents are highly correlated both vertically and across the northeastern slope. Maximal mean values occur $50-100 \mathrm{~m}$ above the bottom in 400 -m-deep water. They are directed along the slope toward the coast in the northwest. A single dominant EOF mode captures about $77 \%$ of the variance at each of three mooring locations that describes the subsurface jet. Jet amplitudes average about $0.1 \mathrm{~m} \mathrm{~s}^{-1}$, but amplitudes twice this value occur 2-3 times during the winter of 2014/15 and 2015/16.

Variability about the seasonal cycle is minimal in summer (Fig. 9) when the sea ice cover is mobile, but local winds are weak. In contrast variability is maximal during December and January when the sea ice is less mobile or even landfast over much of the coastal continental shelf, but both winds and wind stress curl are maximal, especially seaward from our measurement locations.

Spectral analyses of temporal EOF amplitudes suggest that variance of the subsurface jet has distinct peaks at 20-, 11-, and 6-day time scales. Furthermore, we find that about $70 \%-75 \%$ of the ocean current variance at these time scales correlates across the sloping topography. This high correlation gives stable estimates of the phase relation of oscillatory signals. More specifically, correlated signals propagate from shallow into deep water with speeds ranging from about $3.2 \mathrm{~km} \mathrm{day}^{-1}$ near 20 days to $6.8 \mathrm{~km} \mathrm{day}^{-1}$ near 6 -day periodicities (Table 3).

We interpret these propagation speeds as phase velocities of linear topographic Rossby waves (Pickart and Watts 1990; Harden and Pickart 2018) that have wave lengths between $93 \mathrm{~km}$ (6.5 days) and $131 \mathrm{~km}$ (19.3 days). Comparing estimated angles of the wave vector relative to the orientation of the topography against those predicted from linear Rossby wave theory (Rhines 1970), we find excellent agreement even though both observed and predicted angles are small, about $1^{\circ}-4^{\circ}$ from upslope. The observations also reveal smaller angles for lower frequencies which is a property predicted 

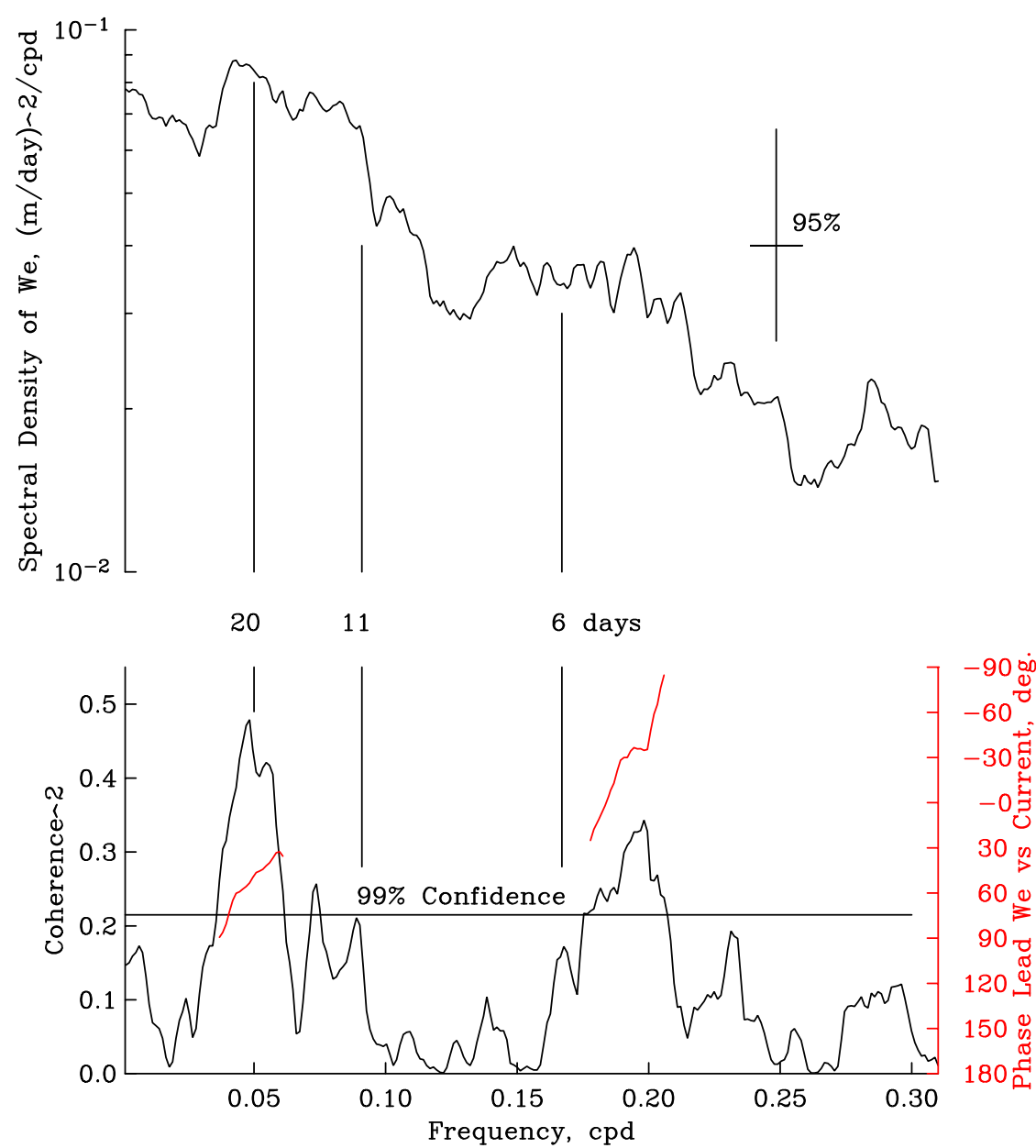

FIG. 15. (top) Power spectral density of vertical Ekman pumping velocity $W_{e}$ near the shelf break at $8^{\circ} \mathrm{W}$ and $76.5^{\circ} \mathrm{N}$ latitude and (bottom) coherence with along-slope currents. Phase between $w_{e}$ and bottom currents at 351-m depth at BG60 is shown in red only at frequencies with nonzero coherences at $99 \%$ confidence; positive phase indicates that a positive (upwelling) $w_{e}>0$ leads a negative (landward) flow $u<0$. See Figs. 12 and 16 for coordinate system and time domain representation of the 20-day signals.

by linear theory that is not always observed consistently (Pickart and Watts 1990; Kanzow and Zenk 2014). Some of our agreements with theory are likely fortuitous, however, because random errors impact our estimates of the orientation of the wavenumber vector. For example, we do not know the orientation of the topography well enough to ensure phase propagation with shallow water on the right as required in the Northern Hemisphere.

Furthermore, cross-spectral estimates have phase uncertainties larger than $2^{\circ}$ and nonsteady wave scattering may occur along irregular smaller scale topography. Nevertheless, our quantitative wave estimates are consistent within the array and agree well with linear wave theory that predicts a group velocity of about $63 \mathrm{~km} \mathrm{day}^{-1}$ along the slope toward the coast. This suggests a wave generation source seaward from our mooring site. We identify the generation region as the area of high correlation of wind stress near the surface and ocean currents near the bottom. More than $50 \%$ of the Ekman pumping variance correlates with the along slope bottom currents more than $180 \mathrm{~km}$ away within the sloping canyon topography.

The dynamics appear linear, because Rossby numbers Ro $=\left[\delta U /\left(f_{0} \delta y\right)\right] \ll 1$. Here we use the lateral velocity differences $\delta U$ across the jet $\left(\sim 0.08 \mathrm{~m} \mathrm{~s}^{-1}\right)$ over a distance $\delta y(\sim 11 \mathrm{~km})$ to find the lateral shear of about $0.05 f_{0}$ where $f_{0}$ is the local Coriolis parameter. The ratio of relative $(\xi \approx \delta U / \delta y)$ to planetary $\left(f_{0}\right)$ vorticity is thus small $($ Ro $\ll 1)$ and nonlinear inertial terms in the momentum equations become negligible (Gill 1982). We neglect small variations of across-slope velocity $\delta V$ 

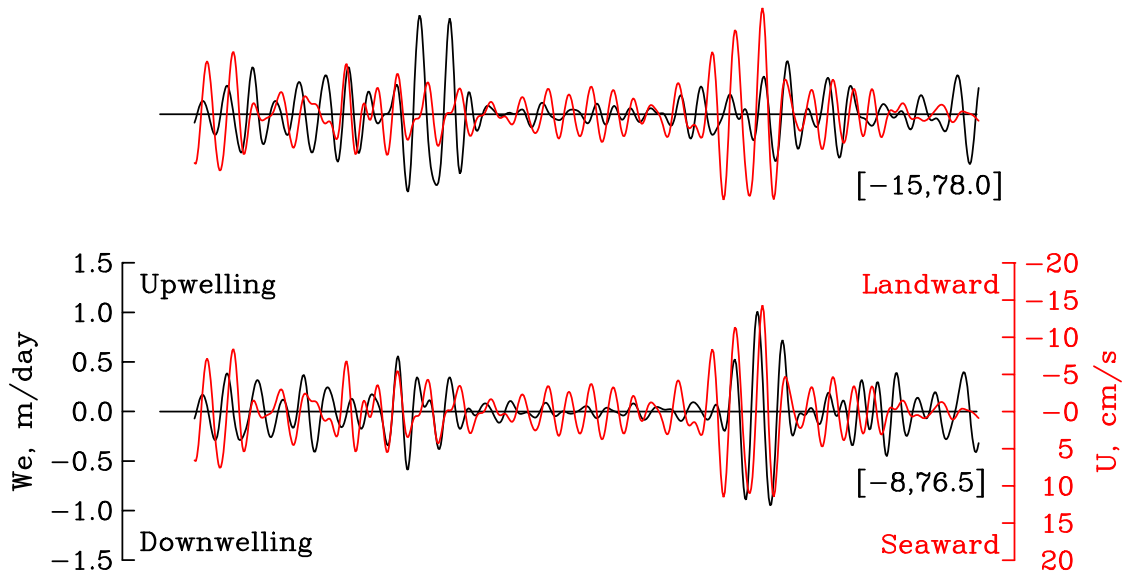

FIG. 16. Time series of bandpass filtered (14-28 days) Ekman pumping velocities at the two locations shown in Fig. 13 in black compared against similarly bandpass filtered near-bottom along-slope velocity in red. (top) Ekman pumping at $78^{\circ} \mathrm{N}, 15^{\circ} \mathrm{W}$ near the mooring location and (bottom) Ekman pumping at $76.5^{\circ} \mathrm{N}, 8^{\circ} \mathrm{W}$ near Fram Strait upstream from the mooring location.

along the slope. For small Rossby number the potential vorticity (PV)

$$
\mathrm{PV}=\frac{f_{0}+\xi}{D} \approx \frac{f_{0}}{D},
$$

where $D$ is the vertical scale of motion. For unforced motions PV is conserved and the flow follows contours of $f_{0} / D$. Such flows are said to be topographically steered.

For barotropic motions $D$ is the water depth $H$ and the steady flow follows depth contours on an $f$ plane. In contrast, our steady (mean) velocity observations are bottom-intensified below the main pycnocline (Fig. 5). Hence our flow is baroclinic and $D$ is the layer thickness below the pycnocline. The flow can move into shallower or deeper water, but in order to conserve PV, the pycnocline moves vertically in unison to keep $D$ constant on an $f$ plane. In steady state geostrophy will balance sloping isopycnals, that is, a bottom-intensified flow moving over a sill into deeper water will be steered to keep shallow water on the right rather than moving into deeper water.

We speculate that our bottom-intensified mean flow is topographically steered and enters Norske Trough near $76.5^{\circ} \mathrm{N}$ from Fram Strait to the north of $77.5^{\circ} \mathrm{N}$ latitude (see Fig. 1). Håvik et al. (2017) report similar waters, density structures, and velocities inshore of the shelfbreak East Greenland Current (EGC). Figure $17 \mathrm{com}$ pares temperature and salinities along this proposed path from northern Fram Strait near $77.5^{\circ} \mathrm{N}$ inshore of the 400-m isobath to our mooring section in the west via the entrance of Norske Trough in the east near $76.5^{\circ} \mathrm{N}$ latitude. The core of Atlantic waters is the temperature maxima near the $27.9 \mathrm{~kg} \mathrm{~m}^{-3}$ potential density anomaly. Over the upstream continental slope this water has a temperature of $3^{\circ} \mathrm{C}$ while at the eastern entrance to Norske Trough in the south its temperature maximum has cooled to $2.5^{\circ} \mathrm{C}$. At our mooring section in the west, we find this maximum near $1.9^{\circ} \mathrm{C}$. The densities are almost identical which suggests mixing with cooler and fresher waters. Coachman and Barnes (1963) present similar data to describe the circulation of Atlantic waters in the Arctic Ocean by tracing the core of this water.

In summary, we posit that our observations describe a topographically steered mean flow near the 400-m isobath, however, the heat of waters that enter Norske Trough and move it toward coastal glaciers do not originate from the EGC. Instead, they originate from the upper continental slope of Fram Strait inshore from the EGC.

The small Rossby numbers motivated our search for remotely forced baroclinic Rossby waves to explain the temporal variations of the observed bottom intensification of currents over the slope at a set of discrete periodicities. We find statistically significant phase propagation of ocean current variability from shallow to deep water. These temporal oscillations modulate the mean flow at periodicities of 20,11, and 6 days. Properties of these oscillations are dynamically consistent with the dispersion relation of topographic Rossby Waves where the bottom slope provides the main restoring mechanism in our rotating and stratified fluid. These propagating waves can be generated by any 


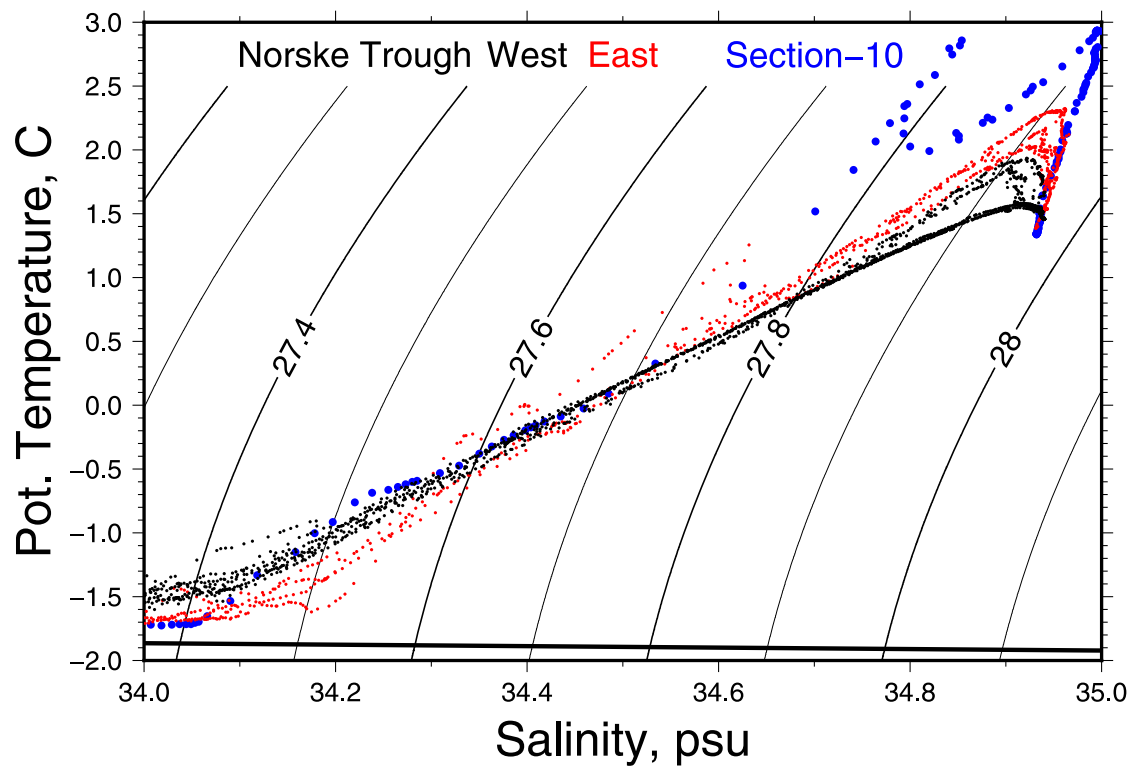

FIG. 17. Potential temperature vs salinity from selected stations along the postulated path of the bottom-intensified and topographically steered flow near the 350-m isobath. Northern Fram Strait data in blue originate from section 10 of Håvik et al. (2017) while data from eastern Norske Trough in red originate from section NT1 of Richter et al. (2018). Black symbols are data from our mooring section; for locations see Fig. 1. Contours are density anomalies, and the thick line is freezing point temperature.

disturbance of the density field. A time-dependent meandering ambient flow such as the EGC can generate perturbations that propagate as topographic Rossby waves (Maslowski 1996). The upwelling or downwelling caused by an eddy crashing into sloping bottom topography, too, can generate topographic waves (LaCasce 1998). While we cannot offer a specific wave generation process for the 11-day oscillation, we describe both a generation mechanism and location for our 20- and 6-day waves via Ekman pumping over the upper slope of Fram Strait.

The evidence presented supports the hypothesis that the wind stress curl over the topographic slope of Fram Strait generates baroclinic perturbations that reach our study area where we detect them as bottom-intensified low-frequency current oscillations. Similar oscillations may exist farther into Norske Trough and perhaps even $79 \mathrm{~N}$ Glacier. It is unclear, however, if the decreasing canyon width and/or its smooth change of orientation will affect the topographic Rossby waves.

The proposed Rossby wave generation differs from the upwelling and downwelling off East Greenland described by Håvik and Våge (2018). Using the same ERA-Interim wind data as we do here, Håvik and Våge (2018) find that coastal upwelling and downwelling favorable winds cause across-shelf currents near the bottom that change the density below the East Greenland Current at $68^{\circ} \mathrm{N}$ latitude. Analyzing wind climatology,
Håvik et al. (2017) suggest that this process diminishes in importance north of $72^{\circ} \mathrm{N}$ latitude.

Within $200 \mathrm{~km}$ of Denmark Strait Harden and Pickart (2018) interpret moored ocean current observations across sloping topography off Iceland as topographic Rossby waves. These waves are represented by the same dispersion relation that we use to describe current oscillations within Norske Trough. Off Iceland the dominant Rossby wave has a period of $\sim 4$ days, wavelength of $\sim 60 \mathrm{~km}$, and an offshore phase speed of $\sim 17 \mathrm{~km} \mathrm{day}^{-1}$. The corresponding onshore group velocity of $\sim 36 \mathrm{~km} \mathrm{day}^{-1}$ suggests an offshore generation region. Harden and Pickart (2018) hypothesize that a meandering East Greenland Current (Håvik et al. 2017) or aspiration of dense waters moving toward the sill of Denmark Strait (Harden et al. 2016) may also contribute to the Rossby wave generation. Hence while their observed wave is similar to ours, the generation mechanism differs.

Our analysis bolsters a hypothesis that a carefully designed experiment can test: Ekman pumping generates topographic Rossby waves over the strongly sloping topography of the Fram Strait shelf break that propagate into canyons that cut across wide shelves off northeast Greenland. The experimental design to test this hypothesis consists of an array of bottom-mounted current meters spaced along the slope of the Norske 
Trough system from Fram Strait to 79N Glacier. Similar physics may impact observable ocean current variability elsewhere near sloping topography.

Acknowledgments. The National Science Foundation supported the initial fieldwork with OPP-1362109 and analyses with OPP-1604076 (AM) while the Deutsche Forschungsgemeinschaft funded JS and TK with KA3204/5-1 as part of the Special Priority Program 1889 "Regional Sea Level Change and Society." Both the University of Delaware and the Alfred Wegener Institute provided substantial additional support with capital equipment and salaries. Instrument preparation, deployment, and recoveries were accomplished through dedicated efforts by a large group of international scientists, engineers, and technicians that included Jonathan Poole and Matthias Monsees. We also thank the captains and crews of R/V Polarstern during PS85 and PS100 as well as Drs. Benjamin Rabe and Wilken Jon von Appen, who supported mooring deployment and recoveries in a safe, efficient, and enjoyable fashion. Drs. Paul Dodd and Laura de Steur of the Norwegian Polar Institute helped with recovery and deployment of M71 and M72, respectively, in 2015. Two reviewers provided detailed and constructive feedback that improved both text and figures.

\section{APPENDIX A}

\section{Compass Heading and Calibration}

Ocean current sensors generally use a flux gate compass to reference direction. While the magnetic field strength vector is constant at a fixed time, it is its horizontal component that turns the "compass needle" as the sensor package changes orientation. This horizontal component decreases with decreasing distance from the magnetic North Pole. In 2015 this pole was about $1100 \mathrm{~km}$ from our study area where the horizontal component was only $7230 \pm 130 \mathrm{nT}$ for the $2014-16$ period of our observations. Furthermore, the local declination $D_{0}$ is $15.9^{\circ} \pm 0.8^{\circ} \mathrm{W}$ and its drift $D_{1}$ is about $0.46^{\circ} \mathrm{yr}^{-1}$. We thus convert the magnetic compass heading $M$ to true north $T=M+D_{0}+D_{1} \times t$, where time $t$ is measured in years. We extracted numerical values from the World Magnetic Model as distributed by NOAA's National Centers for Environmental Information (https://www.ngdc.noaa.gov/geomag).

Our moored ocean current sensing array contains two different mooring designs that are listed in Table 1. Design A places the ADCP package on a mooring line that changes orientation as a result of ocean current drag on the entire $>200 \mathrm{~m}$ mooring line that accommodates additional sensors and buoyancy elements. The ADCP is contained in a stainless steel frame and its batteries are degaussed. This minimizes compass bias, but the sensor package changes orientation by $\pm 180^{\circ}$ in response to variable drag on the mooring.

In contrast, Design B places the ADCP transducers atop a steel float $3 \mathrm{~m}$ off the seabed on a semi-rigid frame that is allowed to pitch and roll, but cannot change orientation. Figure A1 shows 25-month-long time series of pitch, roll, heading and pressure at M20. It shows a stable mooring platform with small pitch and roll near $0.5^{\circ}$ each with deviations from these means always smaller than $0.4^{\circ}$. The magnetic compass starts at about $86.5^{\circ}$ and declines at the predicted rate $D_{1}=0.46^{\circ} \mathrm{yr}^{-1}$ caused by the steady movement of Earth's magnetic pole. Furthermore, we identify five spikes caused by geomagnetic storms of charged solar particles that also cause intense Northern Lights. Observations of these solar flares are distributed by the National Geophysical Data Center (https://www.ngdc.noaa.gov/ stp). The storms cause intermittent compass fluctuations of up to $4^{\circ}$. Our records thus contain a random noise $<1^{\circ}$. The compass on design A moorings contain the drift, solar perturbations, and random fluctuations as well.

Münchow and Melling (2008) introduced this torsionally rigid mooring design B in Nares Strait where magnetic compasses are unreliable. The problem then becomes to determine the (unknown) constant offset or bias of the instrument package that sits fixed on the ocean floor. In Nares Strait $0.5 \mathrm{~m} \mathrm{~s}^{-1}$ strong and rectilinear tidal currents provided a natural coordinate system in the $30-\mathrm{km}$-wide channel, however, no such current or channel exists in Norske Trough and a different method is developed here to determine the unknown constant offset.

More specifically, we employ complex correlation analysis of our observed vector time series with a reference time series. The reference data originate from barotropic tidal predictions of Padman and Erofeeva (2004) that use eight discrete tidal constituents. Our observation-based vector time series results from a tidal harmonic analysis of vertically averaged currents that use the same eight discrete tidal constituents as the model predicts. We thus quantify the constant offset angle from observed tidal current $w_{1}=u_{1}+j v_{1}$ with predicted tidal current $w_{2}=u_{2}+j v_{2}$, where $j=\sqrt{(-1)}$. The complex correlation $c_{12}=\left(u_{1}+j v_{1}\right)\left(u_{2}-j v_{1}\right)$ can be decomposed into a magnitude and an orientation in the complex plane. The orientation angle rotates $w_{2}$ into $w_{1}$ to result in maximal correlation. Table 1 includes this angle at which input and output time series of current vectors result in a maximal correlation. 

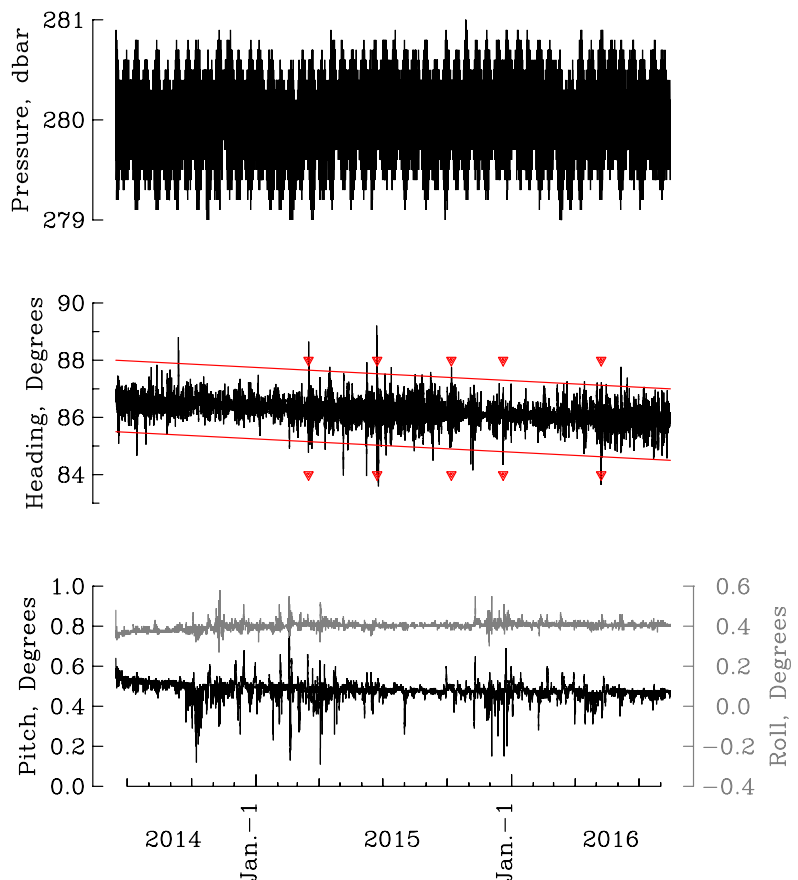

FIG. A1. Time series of (top) pressure, (middle) heading, and (bottom) tilt angles at M20. The magnetic compass heading shows both a steady decline of compass declination (red lines) as well as spikes caused by five identified solar storms (red symbols).

We estimate directional uncertainties to be less than $0.5^{\circ}$, because moorings M50 and M71 result in offset angles of $0.6^{\circ}$ and $0.1^{\circ}$, respectively. These design A moorings do not require compass corrections as their absolute directions are known. Furthermore, the largest uncertainty probably results from uncertain tidal currents in the barotropic Padman and Erofeeva (2004) model that requires accurate bottom depths. Table 1 lists both actual and model depths: at M50 the model depth of $453 \mathrm{~m}$ agrees well with the actual depth of $456 \mathrm{~m}$. In contrast, a large depth discrepancy exists at M71 where the model uses $347 \mathrm{~m}$ when the actual depth is only $250 \mathrm{~m}$. Nevertheless, tidal predictions and observations agree within $0.1^{\circ}$ in direction.

\section{APPENDIX B}

\section{Empirical Orthogonal Functions}

EOF analyses organize serial observations at multiple locations $u\left(t_{k}, x_{j}\right)$ as a set of mutually uncorrelated serial variations $A_{n}\left(t_{k}\right)$ where the spatial dependence is expressed via a structure function $\theta_{n}\left(x_{j}\right)$. The transformation from the vector space of observations $u\left(t_{k}, x_{j}\right)$ to the vector space of uncorrelated EOF modes is linear, that is,

$$
u\left(x_{j}, t\right)=\sum_{n=1}^{M} A_{n}(t) \theta_{n}\left(x_{j}\right) .
$$

Both $\phi_{n}(x)$ and $A_{n}(t)$ are orthogonal in the sense that

$$
\begin{aligned}
\sum_{i=1}^{M} \phi_{n}\left(x_{i}\right) \theta_{m}\left(x_{i}\right) & =\delta_{n, m}, \\
1 / K \sum_{k=1}^{K} A_{n}\left(t_{k}\right) A_{m}\left(t_{k}\right) & =\lambda_{n} \delta_{n, m} .
\end{aligned}
$$

Here $\delta_{n, m}$ is the Kronecker Delta which takes on a value of 1 for $n=m$ and 0 for $n \neq m$.

This heuristic description of EOFs describes a formal eigenvector problem for the cross-covariance matrix $\mathbf{R}$ with elements $R_{i, j}=\sum_{k=1}^{K} u_{i}\left(x_{i}, t_{k}\right) u_{j}\left(x_{j}, t_{k}\right)$, that is,

$$
\sum_{j=1}^{M} R_{i, j} \theta_{m}\left(x_{i}\right)=\lambda_{m} \cdot \theta_{m}\left(x_{i}\right)
$$

where $\boldsymbol{\theta}_{m}$ is the eigenvector of $\mathbf{R}$ for the eigenvalue $\lambda_{m}$. The sum of all eigenvalues $\sum_{m=1}^{M} \lambda_{m}=\sum_{m=1}^{M} R_{m, m}$ represents the total variance which we use to normalize the eigenvalues. In Eq. (B1) we thus scale $A_{n}(t)$ and $\boldsymbol{\theta}_{n}(\mathbf{x})$ such that the eigenvector $\boldsymbol{\theta}_{n}(\mathbf{x})$ carries units of centimeters per second while the eigenfunction $A_{n}(t)$ carries no units and has a variance of 1 for all modes $n$.

\section{APPENDIX C}

\section{Wind Stress in Ice-Covered Seas}

The curl of the surface wind stress generates vertical motion that deforms the ocean density field via Ekman pumping $w_{e}$, that is,

$$
w_{e}=\left(\partial_{x} \tau^{(y)}-\partial_{y} \tau^{(x)}\right) /\left(\rho_{0} f_{0}\right) .
$$

We estimate the wind stress $\tau=\left[\tau^{(x)}, \tau^{(y)}\right]$ from the wind vector $\mathbf{U}=(U, V)$ as

$$
\boldsymbol{\tau}=\rho_{\text {air }} C_{D}\left(U^{2}+V^{2}\right)^{1 / 2} \mathbf{U}
$$

with the density of air $\rho_{\text {air }}=1.32 \mathrm{~kg} \mathrm{~m}^{-3}$ and a drag coefficient $C_{D}$. We use daily surface wind data provided by the European Centre for Medium-Range Weather Forecast as the ERA-Interim product (Dee et al. 2011) to estimate wind stress, its curl, and related Ekman pumping to construct time series and maps of $w_{e}(x, y, t)$. A spatially variable ice cover such as shown in Fig. 3 will result in spatially variable drag coefficients $C_{D}$ that reflect different efficiencies of the momentum transfer from the atmosphere to the ocean (Martin et al. 2014). 
We here implement the parameterization introduced by Lüpkes and Birnbaum (2005) that includes a form drag $C_{f}(A)$ as well as skin drag at ice-ocean $\left(C_{\text {ice }}=1.89 \times 10^{-3}\right)$ and air-ocean $\left(C_{\text {ocean }}=1.25 \times 10^{-3}\right)$ interfaces, for example,

$$
C_{D}=C_{f}(A)+A C_{\text {ice }}+(1-A) C_{\text {ocean }},
$$

where $A$ is the fractional sea ice cover that we take from daily SSM/I imagery at $25-\mathrm{km}$ resolution (Steffen and Schweiger 1991).

The parameterization assumes freely moving sea ice that we do not always encounter on the continental shelf where sea ice becomes landfast in coastal and shallow areas (Hughes et al. 2011). We thus arbitrarily set $C_{D}=0$ when more than $98 \%$ of a pixel is covered by sea ice $(A<0.98)$.

\section{REFERENCES}

Allen, S. E., and B. M. Hickey, 2010: Dynamics of advection-driven upwelling over a shelf break submarine canyon. J. Geophys. Res., 115, C08018, https://doi.org/10.1029/2009JC005731.

Arndt, J. E., W. Jokat, B. Dorschel, R. Myklebust, J. A. Dowdeswell, and J. Evans, 2015: A new bathymetry of the Northeast Greenland continental shelf: Constraints on glacial and other processes. Geochem. Geophys. Geosyst., 16, 3733-3753, https:// doi.org/10.1002/2015GC005931.

Bendat, J., and A. Piersol, 1986: Random Data: Analysis and Measurement Procedures. 2nd ed. John Wiley \& Sons, 566 pp.

Bourke, R. H., J. L. Newton, R. G. Paquette, and M. D. Tunnicliffe, 1987: Circulation and water masses of the East-Greenland Shelf. J. Geophys. Res., 92, 6729-6740, https://doi.org/10.1029/ JC092iC07p06729.

Budéus, G., and W. Schneider, 1995: On the hydrography of the Northeast Water Polynya. J. Geophys. Res., 100, 4287-4299, https://doi.org/10.1029/94JC02024.

,$- \ldots$, and G. Kattner, 1997: Distribution and exchange of water masses in the Northeast Water Polynya (Greenland Sea). J. Mar. Syst., 10, 123-138, https://doi.org/10.1016/ S0924-7963(96)00074-7.

Coachman, L. K., and C. A. Barnes, 1963: The movement of Atlantic water in the Arctic Ocean. Arctic, 16, 9-16, https:// doi.org/10.14430/arctic3517.

Davis, R. E., 1976: Predictability of sea surface temperature and sea level pressure anomalies over the North Pacific Ocean. J. Phys. Oceanogr., 6, 249-266, https://doi.org/10.1175/15200485(1976)006<0249:POSSTA > 2.0.CO;2.

Dee, D. P., and Coauthors, 2011: The ERA-Interim Reanalysis: Configuration and performance of the data assimilation system. Quart. J. Roy. Meteor. Soc., 137, 553-597, https://doi.org/ 10.1002/qj.828.

Freeland, H. J., and K. L. Denman, 1982: A topographically controlled upwelling center off southern Vancouver Island. J. Mar. Res., 40, 1069-1093.

Gill, A., 1982: Atmosphere-Ocean Dynamics. Academic Press, $662 \mathrm{pp}$.

Harden, B. E., and R. Pickart, 2018: High-frequency variability in the North Icelandic Jet. J. Mar. Res., 76, 47-62, https://doi.org/ 10.1357/002224018824845910.
— - and Coauthors, 2016: Upstream sources of the Denmark Strait Overflow: Observations from a high-resolution mooring array. Deep-Sea Res., 112, 94-112, https://doi.org/10.1016/j.dsr.2016.02.007.

Håvik, L., and K. Våge, 2018: Wind-driven coastal upwelling and downwelling in the Shelfbreak East Greenland Current. J. Geophys. Res. Oceans, 123, 6106-6115, https://doi.org/ 10.1029/2018JC014273.

, R. Pickart, K. Våge, D. Torres, A. Thurnherr, W. BeszczynskaMöller, W. Walczowski, and W.-J. von Appen, 2017: Evolution of the East Greenland Current from Fram Strait to Denmark Strait: Synoptic measurements from summer 2012. J. Geophys. Res. Oceans, 122, 1974-1994, https://doi.org/10.1002/2016JC012228.

Hickey, B. M., and N. S. Banas, 2008: Why is the northern end of the California Current system so productive? Oceanography, 21 (4), 90-107, https://doi.org/10.5670/oceanog.2008.07.

Holland, D. M., R. H. Thomas, B. De Young, M. H. Ribergaard, and B. Lyberth, 2008: Acceleration of Jakobshavn Isbrae triggered by warm subsurface ocean waters. Nat. Geosci., 1, 659-664, https://doi.org/10.1038/ngeo316.

Hughes, N. E., J. P. Wilkinson, and P. Wadhams, 2011: Multisatellite sensor analysis of fast-ice development in the Norske Oer Ice Barrier, northeast Greenland. Ann. Glaciol., 52, 151-160, https://doi.org/10.3189/172756411795931633.

Inall, M. E., T. Murray, F. R. Cottier, K. Scharrer, T. J. Boyd, K. J. Heywood, and S. L. Bevan, 2014: Oceanic heat delivery via Kangerdlugssuaq Fjord to the south-east Greenland ice sheet. J. Geophys. Res. Oceans, 119, 631-645, https://doi.org/10.1002/ 2013JC009295.

Jackson, R. H., F. Straneo, and D. A. Sutherland, 2014: Externally forced fluctuations in ocean temperature at Greenland glaciers in non-summer months. Nat. Geosci., 7, 503-508, https:// doi.org/10.1038/ngeo2186.

Johnson, H., A. Münchow, K. Falkner, and H. Melling, 2011: Ocean circulation and properties in Petermann Fjord, Greenland. J. Geophys. Res., 116, C01003, https://doi.org/ 10.1029/2010JC006519.

Johnson, M., and H. J. Niebauer, 1995: The 1992 summer circulation in the Northeast Water Polynya from acoustic Doppler current profiler measurements. J. Geophys. Res., 100, 4301-4307, https://doi.org/10.1029/94JC01981.

Kanzow, T., and W. Zenk, 2014: Structure and transport of the Iceland Scotland Overflow plume along the Reykjanes Ridge in the Iceland Basin. Deep-Sea Res., 86, 82-93, https://doi.org/ 10.1016/j.dsr.2013.11.003.

Kundu, P., and J. Allen, 1976: Some three-dimensional characteristics of low-frequency current fluctuations near the Oregon coast. J. Phys. Oceanogr., 6, 181-199, https://doi.org/10.1175/ 1520-0485(1976)006<0181:STDCOL $>2.0 . C O ; 2$.

LaCasce, J. H., 1998: A geostrophic vortex over a slope. J. Phys. Oceanogr., 28, 2362-2381, https://doi.org/10.1175/1520-0485(1998) 028<2362:AGVOAS > 2.0.CO;2.

Lüpkes, C., and B. Birnbaum, 2005: Surface drag in the Arctic marginal ice zone: A comparison of parameterisation concepts. Bound.-Layer Meteor., 117, 179-211, https://doi.org/ 10.1007/s10546-005-1445-8.

Mardia, K., 1972: Statistics of Directional Data. Academic Press, $357 \mathrm{pp}$.

Martin, T., M. Steele, and J. Zhang, 2014: Seasonality and long-term trend of Arctic Ocean surface stress in a model. J. Geophys. Res. Oceans, 119, 1723-2738, https://doi.org/10.1002/2013JC009425.

Maslowski, W., 1996: Numerical simulations of topographic Rossby waves along the East Greenland Front. J. Geophys. Res., 101, 8775-8787, https://doi.org/10.1029/95JC03799. 
Mayer, C., N. Reeh, F. Jung-Rothenhausler, P. Huybrechts, and H. Oerter, 2000: The subglacial cavity and implied dynamics under Nioghalvfjerdsfjorden Glacier, NE-Greenland. Geophys. Res. Lett., 27, 2289-2292, https://doi.org/10.1029/ 2000 GL011514.

_- and Coauthors, 2018: Large ice loss variability at Nioghalvfjerdsfjorden Glacier, Northeast-Greenland. Nat. Commun., 9, 2768, https://doi.org/10.1038/S41467-018-05180-X.

Mouginot, J., E. Rignot, B. Scheuchl, I. Fenty, A. Khazendar, M. Morlighem, A. Buzzi, and J. Paden, 2015: Fast retreat of Zachariae Isstrom, Northeast Greenland. Science, 350, 13571361, https://doi.org/10.1126/science.aac7111.

Münchow, A., 2016: Volume and freshwater flux observations from Nares Strait to the west of Greenland at daily time scales from 2003 to 2009. J. Phys. Oceanogr., 46, 141-157, https://doi.org/ 10.1175/JPO-D-15-0093.1.

, and E. C. Carmack, 1997: Synoptic flow and density observations near an Arctic shelf break. J. Phys. Oceanogr., 27, 1402-1419, https://doi.org/10.1175/1520-0485(1997)027<1402: SFADON $>2.0 . \mathrm{CO} ; 2$.

— , and H. Melling, 2008: Ocean current observations from Nares Strait to the west of Greenland: Interannual to tidal variability and forcing. J. Mar. Res., 66, 801-833, https://doi.org/10.1357/ 002224008788064612.

Padman, L., and S. Erofeeva, 2004: A barotropic inverse tidal model for the Arctic Ocean. Geophys. Res. Let., 31, L02303, https://doi.org/10.1029/2003GL019003.

Pickart, R., and D. Watts, 1990: Deep western boundary current variability at Cape Hatteras. J. Mar. Res., 48, 765-791, https:// doi.org/10.1357/002224090784988674.

RD Instruments, 1996: Broadband ADCP advanced principles of operation. Field Service Tech. Paper 001 (FST-001), RD Instruments, 15 pp., http://www.teledynemarine.com/Documents/ Brand\%20Support/RD\%20INSTRUMENTS/Technical\% 20Resources/Technical\%20Notes/BroadBand/FST001.PDF.

Reeh, N., H. H. Thomsen, A. K. Higgins, and A. Weidick, 2001: Sea ice and the stability of north and northeast Greenland floating glaciers. Ann. Glaciol., 33, 474-480, https://doi.org/10.3189/ 172756401781818554.

Rhines, P., 1970: Edge-, bottom, and Rossby waves in a rotating stratified fluid. Geophys. Astrophys. Fluid Dyn., 1, 273-302, https://doi.org/10.1080/03091927009365776.

Richter, M. E., W.-J. von Appen, and C. Wekerle, 2018: Does the East Greenland Current exist in northern Fram Strait? Ocean Sci., 14, 1147-1165, https://doi.org/10.5194/os-14-1147-2018.

Schaffer, J., W.-J. von Appen, P. A. Dodd, C. Hofstede, C. Mayer, L. de Steur, and T. Kanzow, 2017: Warm water pathways towards Nioghalvfjerdsfjorden Glacier, Northeast Greenland.
J. Geophys. Res. Oceans, 122, 4004-4020, https://doi.org/ 10.1002/2016JC012462.

—, T. Kanzow, W. J. von Appen, L. von Albedyll, J. E. Arndt, and D. H. Roberts, 2020: Bathymetric constrains ocean heat supply to Greenland's largest glacier tongue. Nat. Geosci., https://doi.org/10.1038/s41561-019-0529-x, in press.

Schneider, W., and G. Budéus, 1995: On the generation of the Northeast Water Polynya. J. Geophys. Res., 100, 4269-4286, https://doi.org/10.1029/94JC02349.

Sneed, W. A., and G. S. Hamilton, 2016: Recent changes in the Norske Oer Ice Barrier, coastal Northeast Greenland. Ann. Glaciol., 57, 47-55, https://doi.org/10.1017/aog.2016.21.

Steffen, K., and A. Schweiger, 1991: NASA team algorithm for sea ice concentration retrieval from Defense Meteorological Satellite Program Special Sensor Microwave Imager - comparison with Landsat satellite imagery. J. Geophys. Res., 96, 21 971-21 987, https://doi.org/10.1029/91JC02334.

Straneo, F., and P. Heimbach, 2013: North Atlantic warming and the retreat of Greenland's outlet glaciers. Nature, 504, 36-43, https://doi.org/10.1038/nature12854.

Sutherland, D. A., and R. S. Pickart, 2008: The East Greenland Coastal Current: Structure, variability, and forcing. Prog. Oceanogr., 78, 58-77, https://doi.org/10.1016/j.pocean.2007.09.006.

- - , and C. Cenedese, 2009: Laboratory experiments on the interaction of a buoyant coastal current with a canyon: Application to the East Greenland Current. J. Phys. Oceanogr., 39, 1258-1271, https://doi.org/10.1175/ 2008JPO4028.1.

Topp, R., and M. Johnson, 1997: Winter intensification and water mass evolution from yearlong current meters in the Northeast Water Polynya. J. Mar. Syst., 10, 157-173, https://doi.org/ 10.1016/S0924-7963(96)00083-8.

Walters, R., and C. Heston, 1982: Tidal-period variations from time-series data using low-pass digital filters. J. Phys. Oceanogr., 12, 112-115, https://doi.org/10.1175/1520-0485(1982) 012<0112:RTPVFT $>2.0$. CO;2.

Washam, P., K. Nicholls, A. Münchow, and L. Padman, 2019: Summer surface melt thins Petermann Gletscher Ice Shelf by enhancing channelized basal melt. J. Glaciol., 65, 662-674, https://doi.org/10.1017/JOG.2019.43.

Yager, P. L., D. W. R. Wallace, K. M. Johnson, W. O. Smith, P. J. Minnett, and J. W. Deming, 1995: The Northeast Water Polynya as an atmospheric $\mathrm{CO}_{2}$ sink: A seasonal rectification hypothesis. J. Geophys. Res., 100, 4389-4398, https://doi.org/ 10.1029/94JC01962.

Zhao, B., and M.-L. Timmermans, 2018: Topographic Rossby waves in the Arctic Ocean's Beaufort Gyre. J. Geophys. Res., 123, 6521-6530, https://doi.org/10.1029/2018JC014233. 